\title{
5 \\ Problems of Kantian Nonconceptualism and the Transcendental Deduction
}

\subsection{Introduction}

At a crucial juncture in the B-Deduction, Kant makes an important distinction. He writes:

To think an object and to know [erkennen] an object are thus not the same. For two components belong to knowledge [zum Erkenntnisse]: first, the concept, through which an object is thought at all (the category), ${ }^{1}$ and second, the intuition, through which it is given; for if an intuition corresponding to the concept could not be given at all, then it would be a thought as far as its form is concerned, but without any object, and by its means no knowledge of anything at all [keine Erkenntnis von irgendeinem Dinge] would be possible, since, as far as I would know [wüßte], nothing would be given nor could be given to which my thought could be applied. (B146; trans. emended)

Here, Kant indicates that there is still important work to be done after completing the so-called 'first step' of deducing the categories from the principle of apperception, ${ }^{2}$ which concerned the necessary form of conceiving of an object in general, since that deduction is incomplete if it 
cannot be shown how the categories apply to objects of human sensible intuition. As Kant writes, "the categories do not afford us knowledge [Erkenntniß] of things by means of intuition except through their possible application to empirical intuition, i.e., they serve only for the possibility of empirical knowledge" (B147; trans. emended). Only by showing the manner in which this application comes about will Kant have explained fully the possibility of empirical knowledge, which he defines as "experience" (B147; cf. B165-6). There has been much discussion in the Kant literature about the role and structure of the second part, the so-called 'second step', of the B-Deduction. However, I am not going to engage with it here directly (see Chap. 7). In this chapter, I am interested more broadly in the extent to which the discussion around Kantian nonconceptualism captures an important, structural aspect of the general argument in, and goal of, the B-Deduction. Most commentators believe that in the second part of the Transcendental Deduction (TD) Kant in fact wants to exclude the possibility that there would be intuitions, perceptions or sensory content to which the categories are not applied or applicable, thus excluding the possibility of so-called 'nonconceptual content'. This is what Kant already appears to suggest at B136 and in the conclusion of the 'first step' of the B-Deduction, at B143, and certainly in the conclusion of the 'second step' at B159ff., in $\$ 26$, where Kant appears to assert that simply everything that comes before our senses is subsumable under the categories. This last position is roughly called 'conceptualism'.

Conceptualism can be defined as the thesis that (1) any conscious, representational content, intuition or appearance is determined by our conceptual capacity and that conscious, representational content, or an intuition or appearance can only refer to objects if and when it is subsumed under concepts, and that (2) non-human (lower animal) beings do not possess such conceptual capacities, by means of which they perceive, and thus refer to, objects in the strict sense. I shall here treat 'intuition', 'appearance', 'representational content' or also 'sensory content' as roughly equivalent expressions, although the latter two are, generally speaking, broader in meaning than the former, and have the infelicitous connotation that the term 'content' might suggest that it is intrinsically 'about' something, i.e. something intentional, 
thus putatively excluding the possibility of nonconceptual content. But since the term has been in use in the debate on nonconceptual content, I shall continue referring to sensory or representational content as signifying material content that is representationally significant in some (subjectively valid) sense, but not necessarily cognitively significant in the demanding sense that Kant associates with objective validity, that is, being about a definite object. On this definition, the term 'nonconceptual content' is thus not an oxymoron. ${ }^{3}$

Conceptualism can be differentiated into strong and weak conceptualism, whereby, if we translate this to the strictly Kantian context, strong conceptualism holds that the understanding, i.e. our conceptual capacity (A68ff./B93ff.), is not only the determining ground of any cognitive judgement, but also of sensibility itself. Weak conceptualism means that, whereas the understanding determines all cognitive empirical judgements, which are based on empirical intuitions, sensibility itself is independent of the capacity of the understanding, and not all conceptual activity (e.g. demonstrative reference) need take place exclusively in the context of explicit cognitive judgements. ${ }^{4}$

By contrast, Kantian nonconceptualists want to argue that Kant does leave open the possibility of intuitions or perceptions that are not subsumed or even subsumable under the categories. ${ }^{5}$ Nonconceptualism is roughly the thesis that (1) not every conscious, objective representational content is merely or at all determined by our conceptual capacity, and that intuitions immediately and independently of concepts perceptually "present" (Allais 2009:384, 386, 389) ${ }^{6}$ objects or particulars to us; that (2) at least some human, objective conscious content occurs independently of our conceptual capacity and is not determined by $\mathrm{it}^{7}$; and that (3) at least some non-human beings (i.e. animals) ${ }^{8}$ have an awareness of some sort of, and are not merely responding mechanically to, their surroundings. ${ }^{?}$

I want to argue that Kantian nonconceptualists are right insofar as the possibility of intuitions that are not subsumed (or subsumable) under the categories is concerned, but that they are wrong to claim (1) that such intuitions are or can be considered synthesised content independently of the understanding or judgement, and (2) that these intuitions are objectively valid cognitions or refer to objects. 
Some Kantian nonconceptualists argue that nonconceptual content is still synthesised content in the sense that it is synthesised by means of figurative synthesis, which Kant distinguishes from intellectual synthesis, which nonconceptualists identify as uniquely characteristic of conceptual content. I argue that, although formally distinguishable, figurative synthesis (a.k.a. the productive imagination) is not possible without intellectual synthesis.

In Sect. 5.2, I discuss the conceptualist position of John McDowell, against which Lucy Allais argues and defends a nonconceptualist reading of Kant; her position is discussed in Sect. 5.4. But before that, in Sect. 5.3, I first discuss the nonconceptualist position of Robert Hanna. Both Allais and Hanna spearheaded the discussion of Kantian nonconceptualism in the mid- to late noughties. I therefore focus on their interpretations. ${ }^{10}$ In Sect. 5.5, I address some conceptualist interpretations of a crucial passage in the run-up to TD, at A89-90/B122-3, which is the best evidence for a nonconceptualist interpretation of Kant. Against these interpretations, both conceptualist and nonconceptualist, I make a case for a moderately conceptualist reading of Kant, which leaves room for nonconceptual mental content in some minimal sense (Sect. 5.6); my reading is different from the aforementioned weak conceptualism in the way that I stress the modally moderate sense in which concept and intuition are related. Additional problems for the nonconceptualist readings of TD are flagged in due course.

\subsection{McDowell on the Relation Between Concept and Intuition}

McDowell (1996, 2009a) presents a view of the relation of concepts to sensory content, to which concepts must in some epistemically relevant way be answerable, that is in an important sense close to Kant's view. Very globally put, the central problem that he is interested in concerns the foundation of empirical knowledge, or indeed, in more Kantian terms, the possibility of such knowledge. In McDowell's view, Kant's epea pteroënta "thoughts without content are empty, [and] intuitions 
without concepts are blind" (A51/B75) hint at the solution to the problem. As Kant asserts, only in the connection of thoughts and intuitions is knowledge possible. This in itself does not give us much in terms of a solution to the problem of the possibility of knowledge. In some sense, we must be able to indicate what makes the connection work and to what extent thoughts and intuitions are effectively connected such that knowledge ensues or is made possible. The unifying element which connects two distinguishable and irreducible items or "two stems of human knowledge, namely, sensibility and understanding" (B29) into a unity concerns what Kant calls synthesis, or as McDowell (2009a:30-33) puts it, "togetherness". I shall say more about this below. ${ }^{11}$

At B151-2, Kant speaks of a connection or combination of representations that is non-intellectual-precisely what McDowell believes is necessary for having empirically contentual thoughts, that is, knowledge that amounts to more than empty thoughts that, to put it in McDowell's terms, "spin in a void", in contrast to concepts that are answerable to the world. Kant calls this non-intellectual connection figurative synthesis (synthesis speciosa) or also the transcendental synthesis of the imagination. This power of the imagination belongs to sensibility and combines the sensible representational material in an intuition into a unity. However, because according to Kant every synthesis is an act of spontaneity, an act of determination (cf. B129-30), ${ }^{12}$ and is not, as with sensibility, that which is determinable or being determined, transcendental synthesis of the imagination is an a priori power that is the effect of the understanding itself on sensibility. After having differentiated figurative from intellectual synthesis in the preceding section, Kant writes:

Imagination is the faculty of representing in intuition an object that is not itself present. Now since all our intuition is sensible, the imagination, owing to the subjective condition under which alone it can give to the concepts of understanding a corresponding intuition, belongs to sensibility. But inasmuch as its synthesis is an expression of spontaneity, which is determinative and not, like sense, determinable merely [bloß bestimmbar], and which is therefore able to determine sense a priori in respect of its form in accordance with the unity of apperception, imagination is to that 
extent a faculty which determines the sensibility a priori; and its synthesis of intuitions, conforming as it does to the categories [den Kategorien gemäß] must be the transcendental synthesis of the imagination. This synthesis is an action [Wirkung] of the understanding on the sensibility; and is the first application [of the understanding] to the objects of our possible intuition. (B151-2; trans. Kemp Smith)

This passage is of central importance for answering the question regarding the relation between sensibility and the understanding, between intuition and concept. I believe that Hegel already saw clearly the relevance of Kant's discussion of the productive imagination for addressing the issue concerning the relation between concept and sensible content. In his early, formative essay Faith and Knowledge, which contains one of his earliest and most sustained expositions of Kant's theoretical philosophy, Hegel points out that with the notion of the productive imagination Kant shows the way in transcending the epistemological dead ends of what Hegel calls "reflective philosophy", which puts up barriers in terms of absolute distinctions between the elements of cognition, of which he accuses Kant too. Hegel interprets Kant's notion of the productive imagination as the power of reason itself, of which the understanding and sensibility are mere derivative forms. In Hegel's view, it is the productive imagination which forms the original-synthetic unity, from which the discursive understanding and sensibility first spring as differentiable elements. In this way, the productive imagination is to be seen as the ground of both sensibility and the understanding ( $\mathrm{GuW}, 4: 327)$ : sensibility and the understanding can first be differentiated, because they are different modifications of the same productive imagination. Productive imagination is what primordially unites concepts and sensory content, which thus solves the problem regarding the foundation of knowledge in sensibility, of how the understanding comes to determine sensible content. For productive imagination is the synthetic a priori, rational principle which is operative in "extension" itself, as Hegel writes (GuW, 4:329, 341), in other words, it is operative in sensibility or intuition itself-it is the very principle of sensibility, as Hegel says (GuW, 4:327). (Hegel's critique of Kant will be explored in detail in Chap. 8.) 
One can detect a similar Hegelian inspired reading of productive imagination as the combinatory factor between concept and intuition, the 'togetherness' of conceptuality and sensible content, in McDowell, who argues that conceptuality is already, in some sense, operative in sensibility. Let me expand. Following Wilfrid Sellars, McDowell believes that "judging is not the only mode of actualization of conceptual capacities" (2009a:5). McDowell takes "judging" to be an act by virtue of our freedom, something for whose content we take responsibility, and for which we are held responsible and must give reasons if asked (cf. Chap. 3, this volume). If we make a claim to knowledge, that is, if there is a "knowing", then we place that which we claim to know in the "logical space of reasons" in contrast to a merely sensible perception, or, being sensibly affected by an object, which as natural fact we place in the logical "space of nature" (McDowell 2009a:4-5). ${ }^{13}$ Judging as such a "knowing" is a typical epistemic fact which must be placed in the space of reasons. In his earlier book (McDowell 1996), McDowell outlined the explanatory problem with which the two classical epistemological theories, foundationalism and coherentism, are faced when trying to explain the justificatory basis of knowledge claims. What is interesting in this context is that in order to get out of this epistemological cul-de-sac McDowell appeals to Kant's above-quoted adage that thoughts without intuition are empty and intuition without concepts blind. To guarantee a critical naturalism or empiricism which is not a reductive physicalism, our conceptuality, and hence our claim to true knowledge, must somehow eventually be grounded in what Sellars (1997:68-73) calls "observation reports", and these, in turn, in sensible intuition or perception. Sensible perception must provide the justificatory ground of our knowledge claims, albeit that such "observation reports" themselves in turn necessarily rest on a perspective on the world (McDowell 2009a:6-7).

What McDowell picks up from Kant, partly following Sellars, is the belief that the manner in which our knowledge claims are grounded in sensibility, in such "observation reports", is not one of being grounded in a purely given sensory content, ${ }^{14}$ such as sense data or factual objects in the world. The crucial point is that whatever necessary sensible content must be presupposed for knowledge, it will not as merely 'given' provide 
the justificatory ground of knowledge. In the above-quoted passage at B151, Kant makes clear that the productive imagination, which bridges the gap between concept and intuition and so presumably provides the justificatory ground of knowledge, is not sensibility itself, which must be determined; rather, it is the determinative or determining element that provides this ground, since it is an "exercise of spontaneity" (Ausübung der Spontaneität) that alone can provide justifications for our beliefs. ${ }^{15}$ Despite this, the productive imagination belongs to sensibility, which makes it properly answerable to the world of sensible objects.

Herein, McDowell sees the solution to the problem concerning the correspondence between concept and intuition, between judgement and perception. Perception itself, by virtue of this spontaneity in sensibility, provides us with the justificatory basis of knowledge, which is, however, only first explicitly articulated conceptually in judgements. The sensible episodes of a perceptual experience "contain" already "a claim", as McDowell (2009a:10-12) ${ }^{16}$ contends following Sellars. A perceptual experience is not merely an observation report, but is itself already intentionally directed towards the world. Perceptual experiences are not merely episodes of sensible content or even consciousness or awareness but already "actualizations of conceptual capacities" (2009a:10), if not yet fully-fledged judgements. In this way, however, the Kantian distinction between concept and intuition is not sublated, for-as McDowell (2009a:11) makes it clear-it being the case that we judge that things are as they appear to us in the way that they are, the fact that they appear to us in a certain way is not the same as judging that they so appear. The epistemic fact of judging is not reducible to the natural fact of the sensory affection, nor is the latter reducible to the former. Formally, concept and intuition, or, judgings and percepts, are separable. But in an actual episode of perceptual experience they are always already inextricably connected. In McDowell's view, the intuition of an empirically given object is already a proto-judgement, which pre-forms, as it were, the objective predicative locution proper in an actual judgement that has the predicative form $S$ is $P$.

Also apparently important here is heeding the distinction between a singular representation or sensation and a self-standing intuition, whereby Kant's singularity criterion for intuition is emphasised 
(see B41; B47; A19/B33; B377). Presumably, an intuition is by definition always already a perceptual experience of an object or a particular, not just an aggregate of representations (I believe that the distinction is not as clear-cut as some would make it out to be, for in Kant's view sensations are just the empirical content of any empirical intuition, which connects it to objects; see A19-20/B34). As a demonstrative 'this here', such an experience is already conceptual. This narrow definition of intuition, as separable from sensations, plays a significant role in the debate surrounding nonconceptual content (I shall return to this aspect further below). According to both McDowell and Sellars, intuitions are thus already conceptual, in some sense. In contrast to McDowell, Sellars (1992:8) wants to retain though the idea of "sheer receptivity", namely the purely being receptive to impressions or impingements of the external world which as such are not conceptual. McDowell (2009a:16) sees no epistemically explanatory or transcendental role for "sheer receptivity". At first blush, it is indeed difficult to see what transcendental function "sheer receptivity" can fulfil for the explanation of epistemically relevant perception, ${ }^{17}$ in addition to acknowledging, as we saw McDowell do, that the fact that things appear to us (are "received" by us) is not the same as judging that they so appear.

For McDowell, the inseparability of concept and intuition is important for understanding the way in which we orient ourselves in the world, are directed towards the world, as well as the manner in which the world is as it were preformed for our actual judgements about the world. McDowell insists, time and again, on the fact that knowledge is grounded in the connection between concept and intuition and that without this connection no knowledge is possible. This reveals his Kantian credentials. McDowell (2009a) demonstrates how Kant's Leiffaden in the Metaphysical Deduction (MD) provides the key to the solution to the question of the justificatory ground of our knowledge claims. Kant writes:

The same function that gives unity to the different representations in a judgment also gives unity to the mere synthesis of different representations in an intuition, which, expressed generally, is called the pure concept of the understanding. The same understanding, therefore, and indeed by 
means of the very same actions through which it brings the logical form of a judgment into concepts by means of the analytical unity, also brings a transcendental content into its representations by means of the synthetic unity of the manifold in intuition in general, on account of which they are called pure concepts of the understanding that pertain to objects a priori [...]. (A79/B104-5)

The Leitfaden indicates - and let me put this in the slightly misleading terms McDowell (2009a:33-35) uses - that the "togetherness" of items in judgements and between inferentially linked series of judgements, that is, a conceptual or logical "togetherness", is also actualised on the level of sensibility. McDowell's (2009a:29ff.) understanding of the Leitfaden shows that he has in any case understood well that the same conceptual operationalisation-Kant speaks of "the same function"-is active on two formally distinguishable levels, on the sensory as well as the conceptual level, within an actual empirical judgement. ${ }^{18}$ The role that perceptual experience plays is not a question of the putative givenness of sense data or some blind intuition on which judgement only post hoc imposes its conceptual structure. On the other hand, according to McDowell perceptual experience is also not an act of free agency, as is the case in judgement proper. It is formally distinguishable from a judgement and at the same time it contributes to knowledge inseparably from judgement.

This last point concerning the distinguishability of a perceptual experience appears to contradict Kant's own idea of productive imagination as an act of spontaneity, because for Kant any conceptual operationalisation can only be a spontaneous act of the understanding. McDowell exploits Kant's distinction between receptivity and spontaneity without granting an epistemic role to Sellars's "sheer receptivity". According to McDowell, a perceptual experience, which is a conceptual episode and not merely a sense impression or a mental state that is prompted by a sense impression, already "contains a claim", whose content precisely corresponds to the content of a judgement. The difference, however, between perceptual experience and an actual judgement lies in the fact that the "actualization of conceptual capacities" in a perceptual experience is "involuntary" (McDowell 2009a:12). This is the reason 
why McDowell wishes to talk about "actualization" and not about an "exercise" of "conceptual capacities" in sensibility (see e.g. McDowell 1996:10). ${ }^{19}$ Free exercise, as spontaneity, is in McDowell's view restricted to an actual judging, which is eo ipso predicative in nature, and not merely a perceptual experience. Conversely, a perceptual experience is not predicative.

This is an ingenious way of reading Kant's account of the conceptintuition relation. However, it is problematic both systematically and interpretatively. McDowell regards the act of judgement very much as an effective control one has over "one's cognitive life" (2009a:11), in contrast to perception, in which logically there is an at least partly involuntary reaction to an external object which affects me from the outside and over which I thus have no control. McDowell (2009a:12) refers to an enunciation of Sellars's, who expresses the conceptual in a perceptual experience in terms of a "claim [which] is, so to speak, evoked or wrung from the perceiver by the object perceived" (Sellars 1997:40; emphasis added). In contrast to "knowings", "seeings"-i.e. "epistemic seeings" in Dretke's sense ${ }^{20}$ — contain claims and thus are conceptual episodes in such a way that these claims are "necessitated" (McDowell 2009a:12) by the object of perception. Sellars appears to exploit the English term 'impression' by pointing out that that which a perceptual experience contains in terms of a claim is 'impressed', as it were, upon the subject of perception.

In the context of McDowell's as well as Sellars's qualified empiricism, it is understandable that a strict distinction is maintained between passive sensibility and the judging subject, who actively 'directs herself' intentionally to the object of perception. At the same time, McDowell wants to stress the fact that there is already, inchoately, a sense of intentionality present in perceptual experience itself. A perceptual experience, as sensible awareness, is itself already intentionally directed at the world, as McDowell argues. Significantly, McDowell says that the German Anschaunng would be best translated as "a having in view" (2009a:260), rather than as 'intuition'. The key question is how the actualisation of conceptual capacities in perceptual experience is effectively achieved if it does not occur by means of an exercise of spontaneity, that is, an act of the understanding. There is nothing conceptual about sensible states 
as such-something that is underscored by Sellars's distinction between, on the one hand, "sheer receptivity", the de facto receiving of sensations, and perceptual experience, on the other. For McDowell, however, it cannot be the case that a perceptual episode is not in principle an item for judgement (2009a:19, 21n.32, 264). This makes McDowell's position quintessentially conceptualist. That is, for McDowell perceptual episodes are conceptually laden or permeated and have always already intentionality, even if independently of an effective act of the understanding (that is, independently of an actual judgement). They always already have the world in view, even though it is true to say that sensations qua sensations have that intentionality only "vestigially" (McDowell 2009a:121). The unity that is realised by the productive imagination is not "an amalgam, however intimately bound together, of components that belong severally to sensibility and understanding" (McDowell 2009a:124); on the contrary, as Hegel emphasised (GuW, 4:329), it is a unity which already lies in perceptual experience, it is as it were 'immersed' in sensibility itself. Hence, the directedness to the world must also already be contained in sensibility itself, by virtue of the productive imagination's "actualization of conceptual capacities" in intuition. As McDowell observes, "the unity of intuitions is not prior to and independent of the unifying capacities of the understanding" (2009a:101).

But where does that leave the activity of the apperceiving subject who is conscious of her manifold sensations as her own and is a fortiori conscious of the unity which she herself puts into the manifold in intuition that she regards as her own? What is the role of self-consciousness in the actualisation of conceptual capacities in intuition? McDowell considers his reading of the relation between conceptuality and intuitions as authentically Kantian. It is unclear, however, how McDowell visualises the effective "actualization of conceptual capacities" in sensibility if it is not achieved by means of the understanding; furthermore, such a view of productive imagination contradicts Kant's view that productive imagination is an "exercise of spontaneity" by the understanding, a legislative power or activity, and precisely not an "involuntary" necessitation by the external object that affects me. As I argued in Chap. 3, Kant's conception of spontaneity in the context of making judgements about empirical objects is such that it must be seen as a spontaneity 
that is necessarily linked to receptivity of sense impressions; hence, it is a relative spontaneity, unlike the absolute spontaneity of our moral will. However, it is nonetheless the spontaneity of the understanding, by way of the imagination, which alone conceptually determines intuitions given in sensibility; receptivity only plays the role of providing sense impressions.

There is nothing involuntary about the imagination's conceptual capacity in sensibility that determines our apprehension of impressions of objects. As Robert Pippin, reflecting on Sellars's views, rightly notes, it is not the case that "some sort of mental activity is merely triggered into operation, or let us say, occurs non-apperceptively", in other words, "the 'evoking' by a red object in sunlight of 'this is red' from a person who knows the language to which this sentence belongs is 'no mere conditioned response" (2013:381-382). McDowell would probably agree on this last point, because we have seen him argue that in sensibility there is an actualisation of conceptual capacities that is not due to just the mere reception of impressions, but it is unclear to me what role, if any, McDowell accords the apperceptive spontaneous subject in such actualisation. What for Kant is clearly an act by the apperceptive subject, McDowell wants to prise apart from any active role on the subject's part.

It is thus not surprising that McDowell talks about "togetherness" instead of "synthesis", a term he anxiously avoids, as it might imply the activity of synthesising. "Togetherness", by contrast, conveniently lacks the connotation of activity. McDowell even asserts, when he does mention synthesis, that "[m]ere synthesis just happens, it is not our doing, unlike making judgments, deciding what to think about something" (2009a:35). Synthesis is however not something that just happens. According to Kant, at least in the B-Deduction, ${ }^{21}$ the productive imagination or figurative synthesis is "an action [Wirkung] of the understanding on the sensibility" (B152; trans. Kemp Smith ${ }^{22}$ ), and synthesis is always "an act of [the subject's] self-activity" (B130). The synthesis of the imagination is not a synthesis that is distinct from the synthesis of the understanding, but is rather the effect of the synthesis of the understanding in sensibility itself; it is in sensibility that the understanding's synthesis manifests itself as the synthesis of the productive imagination, as a figurative rather than a merely intellectual synthesis (cf. again B151-2) (see further Chap. 7). 
The unity that lies in perceptual experience is the unity that is put into the sensory content by an active subject, who is conscious of her act of judgement. ${ }^{23}$ The knowledge which the perceptual experience yields is not knowledge that merely results from the "togetherness" of sensibility and understanding that is subsequently expressed propositionally in a judgement. Such "togetherness" would always be a merely contingent connection and not the necessary connection that is required for knowledge, and, importantly, must be recognised as such by the agent of judgement. An act of recognition must lie at the foundation of a necessary connection (cf. B130; Chap. 6, this volume); however, such an act is not, as McDowell believes, a mere control over one's cognitive life. What Kant means by a synthesis which is active on the level of sensibility itself is the subject's own act of consciously taking responsibility for her conscious life, for all of her sensations and perceptual experiences as her own. Of course, McDowell (2009a:72n.8) is right that it cannot be the case that the subject is continuously selfreflective or inspecting herself. However, by construing 'activity' too reflectively (2009a:71) or indeed psychologically, as if some 'muttering to oneself' were at issue (which is not at all what Kantian subjectivity is about), McDowell underestimates the fact that for Kant the justificatory ground of our knowledge claims lies, not in sensibility itself, no matter how conceptually loaded, but in the apperceiving act of the understanding, in the act of judgement, alone (cf. A106-7) (see again Chap. 3). ${ }^{24}$

I believe that McDowell is thus wrong in claiming that "[n]ot all instances of that kind of unity [he means the 'togetherness' which lies in perceptual experience] need to be seen as resulting from free cognitive activity" (2009a:72). It may be obvious that certain kinds of connection-e.g. purely subjective associations of representations, or indeed the contingent arrays in which an arbitrary series of representations are prompted in the mind and isomorphically correspond to physiological sensations in the brain, which in their turn are physiologically linked up with the body-are not strictly speaking the product of spontaneous cognitive activity in the sense of Kantian apperception or a priori synthesis. A Kantian argument can be formulated to the effect that such contingent connections are in fact not due to the spontaneous activity of the understanding (see Schulting 2012a). However, Kant is clear 
as to the fact that the combination at issue, combination in the strict sense of a priori synthesis, "can never come to us through the senses, and therefore cannot already be contained in the pure form of sensible intuition" (B129; emphasis added). This is so, "for it is an act of the spontaneity of the power of representation" and "all combination [...] is an action of the understanding", which "we would designate with the general title 'synthesis" (B129-30). ${ }^{25}$ Kant means a specific, a priori, necessary and hence a priori intelligible necessary connection and not just any causal connection that just results from being contingently, a posteriori affected by or being impressed with sensory content (on these issues see again Chap. 3). In contrast to McDowell, Kant thus stresses that it is the subject who a priori puts the combination into the object, and so into the manifold of intuition. The combination or "togetherness" is therefore a result of the activity of the cognising subject, not something that is encountered as already contained in the sensible manifold, in any mere perceptual episode.

In a later essay (McDowell 2009b:264-265), however, McDowell abandons the language of "togetherness" and advances a somewhat different reading of the relation between the unity of intuition and the unity of judgement, which there he regards as more intimate. With reference to the Leitfaden passage, he asserts that both the unity of intuition and the unity of judgements are grounded in "an operation of the same unifying function", just as Kant says. The unity of intuition might be said even to be due to the power to judge, but McDowell is adamant that it still not be seen as a conscious discursive activity, in the way that connecting concepts in a judgement is-even though he stresses that it is neither a "pre-discursive" activity. To put the point differently, in McDowell's own words, "even though the unity-providing function is a faculty for discursive activity, it is not in discursive activity that these [conceptual] capacities are operative in intuitions" (2009b:265; emphasis added). So while McDowell is more aware of the one single ground of both unities, he still prises the activity in intuition apart from the discursive activity of explicit conceptual utterances. As with the earlier expounded views of McDowell, this reading is faced with the difficulty of how to account for the way in which the "actualisations of conceptual capacities" in intuitions effectively do become explicitly propositional 
content in judgements, and so fails to explain Kant's central question about the possibility of knowledge, which for Kant is allied to the question of synthetic a priori judgements. ${ }^{26}$

This problem is exemplified by McDowell's emphasising that the conceptual content of an intuition is "in the intuition in a form in which one could make it, that very content, figure in discursive activity"-he speaks of a "potential for discursive activity" (2009b:265). In this way, McDowell introduces a modal element, which makes it difficult to understand what makes the unity of intuition subsequently become an actual judgement if it is the same function, by means of the same actions, that operates both in intuition and at the level of judgement. ${ }^{27}$ On McDowell's reading, it appears that either there are-despite his insistence to the contrary-in effect two functions, which operate separately at distinct stages of the cognitive process-in perceptual experiences and in judgings, or there is indeed one function, but which operates in separable contexts and under different conditions, namely, either as non-discursive activity in an intuition or as discursive activity in an actual judgement-which begs the question as to what binds the two functions or, if there is still one function, its distinct operations or activities, in cases where there is in fact a genuine judgement about a perceived object, which "redeploys some of the content of the intuition" (2009b:266), to use McDowell's phrase. McDowell (2009b:270) talks about a potentiality of the intuitional content being actualised in a discursive "tak[ing] to be so"; but it is unclear how McDowell envisages by what means the potential is actualised or realised. The modal talk about the potential for conceptual content (in intuition) becoming actualised stands in tension with the claim that the unity of intuition and the unity of judgement are due to the same conceptual capacities, even to the same capacity to judge; if the same function is the ground, both of the potential conceptual content of an intuition and of the actual conceptual content of a discursive judgement, then the actualisation of the potential in an intuition cannot rest on that same function, but requires another, additional function. ${ }^{28}$

But of course, for Kant, the "same function" of synthesis is precisely intended to be the single original function that already binds concepts and intuitions at the most fundamental level, beyond which there 
is no further, even more fundamental function, by means of which the content of intuition "could [...] figure in [the] discursive activity" (McDowell 2009b:265) of a judgement. It seems that McDowell misapprehends the a priori nature of the synthesis of concept and intuition that is at issue in TD. If a priori synthesis is supposed to ground the relation between intuition and concept at the fundamental level, then there is no more original function, by virtue of which the content of intuition can, in a (possible) subsequent stage of cognition, become, or "enable" (McDowell 2009b:266), the content of explicitly discursive activity. The intuitional content either is or is not the content of such discursive activity, as that activity is operative in judgement. Intuition does not enable a judgement, it is the content of a judgement, or it is not.

McDowell acknowledges that "much of the content of an ordinary visual intuition, the capacities that are in play in one's having it as part of the content of one's intuition are not even susceptible of discursive exercise" - he mentions the "finely discriminable shapes and shades of colour that visual experience presents to one" (2009b:265; emphasis added). Such content is clearly not content that figures in judgements. But this stands in tension with his other claim that "an intuition's content is all conceptual", in the sense that it has the disposition to be made to "figure in discursive activity" (McDowell 2009b:265), that is, in judgements. Such a view begs the question against the (essential) nonconceptualist, who denies that intuitional content is conceptual, let alone must figure in judgements (although it could) — a position we shall consider in the following sections.

Concluding my exposition on McDowell, it becomes apparent that McDowell's more phenomenologically inclined view on the intentionality towards objects and Kant's transcendental analysis of the possibility of synthetic a priori knowledge claims articulated in judgements, given the actuality of such knowledge claims, constitute two different perspectives. In Kant's account the perspective is consistently from the vantage point of the judging subject that makes empirical claims about objects and is aware of so judging, whereas McDowell's view shows more a kind of two-stage bottom-up analysis from perception, in which the selfconscious subject does not (yet) figure; indeed, he makes it clear that non-propositional experience, that is, the non-discursively "bringing 
our surroundings into view" in intuition, "is not taking things to be so" (McDowell 2009b:269; emphasis added), which is what we first do in judgements. On this reading, although McDowell contends that both intuition and judgement have the same conceptual content, one can have an intuition of an object as red, say, entitling one to judge that the thing perceived is so, without in fact having to explicitly judge that the object is so; only the latter activity entails the possibility of explicit rational reflection. ${ }^{29}$

The deflationary reading of the role of subjectivity for the actualisation of the connection in the representational material or sensory content of an intuition, and the failure to heed the a priori nature of synthesis, is also characteristic for an interpretation that is at least in one important sense diametrically opposed to McDowell's conceptualist construal of the relation between concepts and intuition. In the next two sections I expand on that reading.

\subsection{Hanna's Nonconceptualism}

Against the traditionally conceptualist reading of Kant's argument about the relation between concept and intuition, Hanna $(2005,2008)^{30}$ defends the existence of non-conceptual content. According to Hanna, the thesis of the nonconceptuality of mental content (hereafter nonconceptualism for short) rests on the idea

that representational content is neither solely nor wholly determined by our conceptual capacities, and that at least some contents are both solely and wholly determined by nonconceptual capacities and can be shared by human and non-human animals alike. (2008:42)

Hanna pits this thesis against the thesis of conceptualism, which says that mental content is wholly determined by conceptual capacities and that the psychological states of non-human beings (animals) lack mental (representational) content. ${ }^{31}$ Hanna (2008:44) asserts that perceptual states exist whose representational content is not, not even in principle, conceptual. This does not imply that such states lack representational content. 
Hanna provides philosophical evidence independently of the Kantian context, but he also contends that the existence of such states can be proven by virtue of the very passage from the Critique quoted by McDowell in support of his conceptualism, viz. that " $[\mathrm{t}]$ houghts without content are empty [and] intuitions without concepts are blind" (B75). On the basis of this and other passages (e.g. B122-3; see further below the discussion in Sect. 5.5), Hanna regards Kant not only, like most interpreters of Kant, as the founder of conceptualism, but also and foremost as the founder of nonconceptualism. According to nonconceptualism, intuitions can indeed be given without concepts being required, just as concepts are thinkable without (sensible) intuition.

Hanna (2008:45-46) aims at a "bottom-up" theory of human rationality. That is to say, he has in mind an analysis of the

two-way ladder by which the world is consciously delivered up from embodied animal experience to self-conscious thought and actionoriented deliberation, and then is downwardly transformed by our thinking and action under universal a priori norms. (Hanna 2008:62-63)

To this end, he distinguishes between first-person information processing and subpersonal information processing. Although it is nonconceptual and non-self-conscious, subpersonal information processing takes place from the first-person perspective and involves consciousness (Hanna 2008:59). Hanna argues for the distinction between self-consciousness and "sensorimotor subjectivity" (2008:59), which is the primitive capacity of conscious, neurobiological beings and which is based on primitive bodily consciousness, such as proprioception, kinaesthesia, orientation, feeling of pain, etc. The central, and valid, philosophical point that Hanna makes concerns the fact that "self-consciousness or self-reflection requires sensorimotor subjectivity, but sensorimotor subjectivity does not require self-consciousness or self-reflection" (2008:59).

Confirmation of this viewpoint is provided by the famous case of blind-sight patients who are able to perform acts of which they are at the same time not self-aware of performing them. It would be very implausible to assume that such patients "are mere robots in the blind 
areas of their self-conscious visual fields" (Hanna 2008:60-61). Hanna associates this with Kant's notion of blind intuition (B75-6). An intuition is blind if a self-conscious, conceptual processing of information does not take place, but at the same time such an intuition is representational content which involves sensorimotor subjectivity in what Kant calls inner sense. According to Hanna, an intuition is always conscious mental content and also directly refers to an object. Blind intuition is "essentially non-conceptual content" (Hanna 2008:62). ${ }^{32}$ Nonconceptual content is characterised by its own "lower-level spontaneity" (Hanna 2008:62), which Hanna associates with Kant's synthesis speciosa or figurative synthesis. Hanna emphasises that the "lower-level spontaneity" is irreducible to "higher-level spontaneity", the synthesis performed by the understanding or the synthesis intellectualis. Also, Hanna argues that "lower-level spontaneity", which knows its own normativity, is the "necessary ground" for the rational spontaneity of the higher level, and that both nonconceptual and conceptual content "are complementary to one another in the constitution of atomic or basic perceptual judgments, or what Kant calls 'judgments of experience"” (2008:62).

Hanna's arguments for the existence of nonconceptual content-one of them is a very illuminating account of Kant's early argument about incongruent counterparts (2008:53ff.) - are sound and in my view convincing. However, his more specific views on Kant in respect of the issues at stake, especially the alleged distinction between "lower-level" and "higher-level" spontaneity, is seriously problematic, both philosophically and as an interpretation of Kant. Interpretatively, it would be difficult, on Hanna's reading, to explain why Kant says that it is "one and the same spontaneity that, there under the name of imagination and here under the name of understanding, brings combination into the manifold of intuition" (B162n.; emphasis added). Hanna postulates the idea that the Sellarsian space of reasons is nothing but "a discursivethat is, a conceptual, judgment-driven, and linguistic - and a priori normative superstructure built on the platform of essentially non-conceptual embodied animal experience" (2008:63; emphasis added). If this were indeed the case-and the language used is significant - then, as Hanna effectively claims, "essentially non-conceptual embodied animal 
experience" would be the epistemically relevant, foundational ground of all rational experience and knowledge; put differently, essentially nonconceptual content would be the exogenous normative constraint of conceptuality.

This is in stark contrast to McDowell's view, who as we have seen maintains that the role of intuition or receptivity cannot be regarded as exercising a normative constraint on our rational claims from the outside. Intuition does not play a constraining role on our conceptuality exogenously, supposedly in a non-conceptual way. The philosophically more pertinent question is how something nonconceptual can in fact be the explanatory, let alone the justificatory ground of the conceptual without falling back into an unwelcome foundationalism, which invites all kinds of vicious infinite regress. McDowell's conceptualist reading does not suffer from this problem, even if it is true that he misapprehends Kant's emphasis on the activity of our rational capacities which connect concepts with intuition, that is, the ineliminable role of subjective agency.

Hanna cannot explain what it is that connects two irreducible and essentially different things, namely, the essentially nonconceptual-i.e. "embodied animal experience" — with what is essentially conceptuali.e. rational thought and "action-oriented deliberation"-in such a way that together they yield objective knowledge. The main philosophical problem comes down to being able to explain how the two irreducibly separable constituents of knowledge, nonconceptual sensible content and the conceptual, do link up so that knowledge can arise from it. This is especially pertinent when the Kantian terminology of figurative synthesis and intellectual synthesis is employed, for regardless of their exact nature Kant at any rate means these differentiable forms of synthesis clearly as operating only in their conjunction. If, as Hanna suggests, figurative synthesis as the lower-level spontaneity corresponds to the nonconceptual and intellectual synthesis as the higher-level spontaneity corresponds to the conceptual, and both are separable, then the operative question is: What connects the figurative synthesis with the intellectual synthesis such that a proper judgement ensues? Which further synthesis is responsible for their synthesis? And how does the threat of an infinite regress here relate to Kant's view that the synthesis at issue in TD is an a priori and transcendental synthesis, that is, an original 
synthesis which grounds any other empirical synthesis and which itself does not depend on an even more original synthesis but should rather be seen as a regress-stopper? ${ }^{33}$

If Hanna were right that figurative synthesis is the necessary ground of intellectual synthesis (2008:62), then it would seem that the lowerlevel spontaneity grounds the higher-level spontaneity, which given the specifics of spontaneity - namely, a self-activity (B130) or causality that is itself uncaused (cf. B430; A533/B561; A445ff./B473ff.) —seems odd to say the least. How does this work? This would surely be to reverse the order of what is ground and what is grounded. How can something that is not caused by anything except itself be grounded in something other that is in any case not more fundamental or original (and in fact, is rather less fundamental)? ${ }^{34}$ At any rate, it conflicts with Kant's view that a priori synthesis is the spontaneous act or "self-activity" of the understanding (B130; B132; B150); there is nothing, certainly not a putative "lower-level" spontaneity, which can ground it, for if there were it would cancel out its very originality. If Hanna intends this grounding to mean that intellectual synthesis, or, the higher-level spontaneity simply latches onto the lower-level, more primitive spontaneity, which supposedly grounds the former, then one can hardly speak of spontaneity in the proper sense of the term anymore (or it should be in terms of merely relative spontaneity; see again the discussion in Chap. 3).

A distinction between a priori synthesis and actual causal connections, a posteriori syntheses, must be heeded. The fact that essentially nonconceptual mental content exists does not eo ipso imply that this content is synthesised content in Kant's sense-i.e. synthesised a priori, that is, synthesised by virtue of necessary synthesis. A proof of the existence of nonconceptual mental content follows analytically from Kant's argument for the unity of self-consciousness. In accordance with the principle of apperception (B131-2), not all conscious content is analytically unified content, namely mental content that is something for me, I being the identical subject aware of my representations as my own. Hence, given that analytically unified mental content requires the categories, mental content that is not so unified is nonconceptual content. ${ }^{35}$ But the same argument will also show that it logically follows that such mental content cannot be synthesised content (in Kant's sense) either, 
given the rigorous coextensivity of the analytic and synthetic unities of apperception (cf. B133). ${ }^{36}$ So nonconceptual content cannot be content synthesised by figurative synthesis. Hanna's assertion that essentially nonconceptual mental content is characterised at least by figurative synthesis is not based on Kant's own argumentation. Although, given the two-step structure of the argument of TD, intellectual synthesis and figurative synthesis are formally distinguishable, figurative synthesis is not really possible without intellectual synthesis having been satisfied, for the act of figurative synthesis is the act of the same understanding which operates both on the "intellectual" or conceptual level of a judgement and the level of "intuition" in a judgement (see A79/B104-5). A more in-depth defence of my claims is required than I can provide here, ${ }^{37}$ but at any rate the passage we have been discussing in the preceding sections, at B151-2, makes sufficiently clear that figurative synthesis does not come apart from intellectual synthesis, since figurative synthesis is the effect of the understanding's own act of synthesis (intellectual synthesis). If you remove intellectual synthesis, you remove figurative synthesis.

One could argue that, in a formal analysis, it would be possible to have an intellectual synthesis that does not imply the instantiation of a figurative synthesis if, for example, one abstracts from the application of the categories to a spatiotemporal sensible manifold and considers discursive modes of cognition that make use of a different way of schematising (cf. B148-9). But the reverse does not hold: one cannot have a figurative synthesis, even analyse it, without presupposing the effective instantiation of an intellectual synthesis, since the latter is a necessary condition for the former. It should also be pointed out that-at any rate in Kant's internalist perspective-such mental contents that are nonconceptual are as such epistemically irrelevant, as indeed McDowell maintains, because they are "nothing to" the self-conscious subject, the conscious 'I' (B131-2). McDowell rightly observes that " $[\mathrm{w}]$ ithout the higher faculty, sensibility can yield at most the representations, merely associatively ordered and so not amounting to cognitions, that Kant allows to non-rational animals" (2009a:119), although I should like to qualify this to the extent that such merely associatively ordered representations occur, de facto and not just hypothetically, also in rational 
animals, human beings. In other words, nonconceptual content has as such no epistemically or transcendentally relevant role to play whatsoever-although of course de facto given sensory content has such a role, just insofar as it must be assumed to be given on pain of there not being knowledge at all; but this requirement is of course not denied even by (strong) conceptualists.

\subsection{Allais's Nonconceptualism}

In her original article on nonconceptual content in relation to the representation of space (Allais 2009), Allais reacts against the standard reading of Kant's theory of the a priori forms of intuition as the condition of the representation of particular objects, and the way concepts are said to be involved in this. This reading amounts to believing that

we cannot be perceptually presented with, or represent, particular things independently of our applying, or having the ability to apply, concepts, and in particular the categories, to these particulars [...]. (Allais 2009:384)

Like Hanna, Allais criticises the view that no mental representational content exists independently of concepts. Allais contends that for Kant it is not necessary to apply concepts to have external particular objects presented to one in intuition. She emphasises that the role of intuition consists precisely in presenting us with particular objects and that intuition plays this role independently of conceptuality. In this way, Allais (2009:384-385) goes against McDowell's (1996:9) assertion that intuition does not make an "even notionally separate contribution to cognition".

Similarly to Hanna, Allais argues for the existence of (relatively) nonconceptual content. ${ }^{38}$ Allais's thesis is that although it cannot be denied that actual intuitions must be conceptualised in order to yield knowledge, it must be denied that intuitions must be conceptualised in order to present us with objects. To claim the latter, namely that intuitions must be conceptualised even to present us with objects, would be to 
argue for "strong conceptualism" (Allais 2009:386). In opposition to McDowell, Allais argues that intuition does make a separable contribution to cognition, which consists in the fact that intuition perceptually provides us with individuals, particular objects, which concepts cannot do. Allais emphasises Kant's definition of intuition as that which, in contrast to a concept, refers immediately to a particular, singular object (cf. A320/B377; A68/B93; A19/B33; B47/A32 ${ }^{39}$ ). The thesis of the blindness of intuition (A51/B75) does not mean, according to Allais (2009:393), that an intuition has no representational value or function. On the contrary, it belongs to the definition of an intuition that it gives us the object. ${ }^{40}$ Allais points out that for an intuition and hence for the perception of a particular object the use of concepts as general rules, as constituents of judgements and thus of the understanding, is not required. ${ }^{41}$ Intuition provides or gives us the object about which we think and it is only in the second instance that the concept enables us to think about the object, or to make judgements about it (Allais 2009:390). This view is confirmed by what Kant writes in his later, unpublished Prize Essay:

By the intuition that accords with a concept the object is given; without that it is merely thought. By this mere intuition without concept the object is given, indeed, but not thought; by the concept without corresponding intuition it is thought but not given; thus in both cases it is not known. (FM, 20:325 [Kant 2002:406])

In contrast to McDowell and Sellars, Allais believes it is important to acknowledge that Kant understands the epistemic role of intuition as such not as merely causal or that intuition would only have an information-processing role. Intuition, by "giving us objects", enables, and so is partly responsible for, objectively valid knowledge (Allais 2009:391). However, although Kant sees intuition as an indispensable source for knowledge, I believe Allais, like Hanna, goes beyond Kant by suggesting that it is intuition that enables the objective reference for our knowledge claims, since objective validity, for Kant, is always and only a function of judgement, hence a function of our conceptuality, not of intuition. It is only in judgement that we achieve genuine reference to objects. ${ }^{42}$ 
In her defence, it should be pointed out though that Allais (2009:405) makes an important distinction between being presented with objects and the presentation of an object as object, which "the non-concepthaving creature is arguably not in a position" to do (cf. Allais 2009: $407,413)$; the presentation with objects would then be a function of intuition, whereas the representation of an object as object would be a function solely of the understanding or conceptuality.

That intuition fulfils an epistemic role independently of conceptuality implies, according to Allais (2009:394), that intuition itself must be attributed a nonconceptual mental processing function. Allais connects this processing function with Kant's synthesis (2009:395). Like Hanna, she associates intuition with figurative synthesis. She considers the possible objection that if intuition requires synthesis and synthesis is always governed by concepts, then intuition must itself also already be conceptual content, just as Kantian conceptualists argue. Allais's reply is that synthesising is not yet or not the same as conceptualising and that "[a]lthough concepts always involve synthesis, it does not follow that synthesis always involves concepts" (2009:396n.35). According to Allais, then, intuition indeed requires synthesis, but synthesis itself is not already conceptual. Allais writes:

To say that we perform syntheses that are governed by the categories (and other concepts), and indeed that we must do this if we are to be able to apply the categories (and other concepts), is not to say that synthesis per $s e$ is governed by concepts [...]. (2009:396) $)^{43}$

Allais is right that the fact that concepts always require synthesis does not imply that synthesis always requires concepts only if she means by the latter that synthesis per se requires "other concepts", i.e. empirical concepts. However, I take it that Allais really means that synthesis does not require the categories, not just empirical concepts. Allais is ambiguous here about which kind of 'concept' is at issue. (Also the oft-used but vague terminology of "governed by" is not helpful here.) If she means 'empirical concept' or just the 'analytic unity of a common mark' shared by a multiplicity of representations - the concept <red>, say, common to the empirical concepts <tomato $>$, <bus 93 to Putney $>$, and 
$<$ Labour $>$ - then of course synthesis is not conceptual and so does not require concepts, for a synthetic unity is by definition not an analytic unity, let alone an empirical concept. However, in the context of TD Kant means 'concept' as 'pure concept' or as "consciousness of this unity of synthesis" (A103), hence as category.

The question regarding the use of empirical concepts, and whether or not they are necessary for the possibility of having an intuition, is not germane to the central question whether figurative synthesis is or is not amenable to categorial determination. ${ }^{44}$ However, the view that "synthesis per se" is not "governed" by, or does not require, the categories, as Allais thinks, must be considered mistaken. That according to Allais synthesis supposedly is not already conceptual would at least appear to be in conflict with Kant's assertion in one of his Reflexionen from the 1780s, where transcendental synthesis of the imagination is said minimally to involve "a concept of the object in general":

The transcendental synthesis of the imagination pertains solely to the unity of apperception in the synthesis of the manifold in general through the imagination. Through that a concept of the object in general is conceived in accordance with the different kinds of transcendental synthesis. $(\mathrm{LBl}, \mathrm{B} \text { 12, 23:18 [Kant 2005:258]) })^{45}$

That Allais does believe that synthesis and categories can come separate shows her misunderstanding regarding the intimate relation between a priori synthesis and the categories, as if a priori synthesis and categorial determination were, or rested on, two wholly separable functions. Rather, the set of categories just is the set of rules for synthesis. Take these Reflexionen:

Now the categories are nothing other than the representations of something (appearance) in general so far as it is represented through transcendental synthesis of imagination [...].

The manifold, however, cannot thoroughly belong to one apperception except by means of a thoroughgoing synthesis of imagination and its functions in one consciousness. This transcendental unity in the synthesis of imagination is thus an a priori unity under which all appearances must stand. Those [i.e., den Functionen derselben $=$ the functions of the 
synthesis of imagination] however are the categories, thus the categories express the necessary unity of apperception under which all appearances belong insofar as they belong to one cognition a priori and necessarily. (LBl B 12, 23:19 [Kant 2005:259])

That the a priori synthesis of the imagination in sensibility and categorial determination are not separable is further made clear by the Leitfaden: a priori synthesis is precisely the way ("the same function") in which categorial determination takes place, on two levels simultaneously, conceptually (intellectual synthesis) and in the sensible content of intuition (figurative synthesis). In any given empirical judgement, a priori synthesis precisely is the 'application' or 'schematisation' of the categories to/in intuition, so that a priori synthesis and categorial determination are coextensive in all possible cases of such judgements. The standard reading is that synthesis is an activity that is separate or separable from the set of categories itself or indeed from categorial determination, but that makes it unintelligible how supposedly by virtue of synthesis the categories get 'applied' (if 'applied' is the proper term). If indeed synthesis and categorial determination were separable functions, which are not necessarily coextensive in all cases, as Allais suggests, the question arises as to which function other than synthesis - and, lest we forget, we are talking a priori synthesis here, naturallywould perform the unification of the synthesis (of the imagination) and the categories. This leads inevitably to an infinite regress. The categories being so many modes of synthesising pre-given manifolds in intuition (Prol, 4:305; LBl B 12, 23:19) and the act of synthesis being the combined set of these modes of synthesising, by implication synthesis cannot be separate from, and so by definition always requires, the categories. ${ }^{46}$

Importantly, Kant's procedure in the B-Deduction is such that the argument of the 'second step', which concerns the analysis of the possibility of knowledge of spatiotemporal objects, is part of the overall argument about the constitutive elements of possible experience. In a certain respect, the argument of the 'second step' is of course independent of the argument of the 'first step', but the order of reasoning is clearly from the analysis of the intellectual synthesis in the 'first step' to the 'second step's argument about figurative synthesis. ${ }^{47}$ Intellectual synthesis is thus a necessary condition of figurative synthesis, but the latter is not 
a necessary condition of the former. Therefore, there cannot be any figurative synthesis (in the sense of Kant's a priori synthesis of the transcendental imagination, which is at issue in the 'second step') that does not presuppose an intellectual synthesis.

Purely formally, in the context of the analysis of TD, there can be an intellectual synthesis without figurative synthesis, namely when we consider forms of discursive synthesis that do not rely on the kind of sensibility the human understanding relies on (cf. B149-50), and so requires a different given intuition to perform its act of synthesising, or indeed, when we study the 'first step' of the B-Deduction in abstraction from the 'second step' (as I myself did in Schulting 2012b). However, a figurative synthesis always presupposes the intellectual synthesis, precisely because it is a more particular instantiation of the intellectual synthesis in human sensibility; as Kant puts it, figurative synthesis is "an effect of the understanding on sensibility and its [desselben] first application [...] to objects of the intuition that is possible for us" (B152; emphasis added). The figurative synthesis is as much an activity carried out by the understanding as is the intellectual synthesis, which is the Verstandesverbindung that is "thought in the mere category in regard to the manifold of an intuition in general" (B151). In fact, given that the figurative synthesis is an effect of the understanding on sensibility, and given that the understanding is the intellectual synthesis in abstraction from empirical intuition (B152), ${ }^{48}$ the figurative synthesis is the intellectual synthesis, as carried out in sensibility, in the context of an actual empirical judgement. Therefore, a figurative synthesis that would be independent of the understanding is simply impossible. The putative independence of figurative synthesis from the understanding is directly refuted by a passage in B164, where Kant affirms that, with respect to the unity of the intellectual synthesis of a sensible intuition, the imagination "depends on the understanding".

Apart from interpretative questions, if figurative synthesis were to be something wholly different from categorial determination, that is, intellectual synthesis, then the question would arise-the same question that arose with Hanna's construal-as to how figurative synthesis is in its turn synthesised with categorial determination or intellectual synthesis, landing us in a vicious infinite regress, the regress that a priori, original synthesis was precisely designed to block. 
Although, as Allais acknowledges, Kant makes it clear at B129-30 that "all combination [...] is an action of the understanding" (emphasis added), ${ }^{49}$ Allais relies on Kant's account of synthesis in the A-Deduction, where Kant more explicitly differentiates the various forms of synthesis, ostensibly only one of which involves concepts, namely the synthesis of recognition; she takes this differentiation to confirm her understanding of intuitional or figurative synthesis, which is identical to the synthesis of the imagination, as nonconceptual. Allais also emphasises Kant's remark in the run-up to TD, after Kant has defined 'synthesis', that synthesis is the effect of the imagination, "a blind though indispensable function of the soul" (B103/A78). (Notice, however, that in the margin of his own copy of the A-edition of the Critique Kant substituted "understanding" for "soul", which is significant to say the least and points to his refashioning of the argument in the B-edition, although it should be noted that he did not in fact replace "soul" in the parallel passage in the B-edition.) It might appear odd for Kant to make the distinction in B103 between synthesis in general and "to bring this synthesis to concepts" if both were indeed to be seen as functions of the same understanding. Nevertheless, in conformity with the Leitfaden, it is precisely Kant's claim that one function of the understanding brings about two syntheses, on both the conceptual level and in intuition, and at the same time (not separately and consecutively). More decisively, as I argued above, in the B-Deduction Kant speaks explicitly of the productive imagination or figurative synthesis as an "effect of the understanding" (B152; emphasis added).

But also in the A-Deduction and before, there is evidence on the basis of which it is questionable to regard each element of the threefold synthesis as a separable source of knowledge. Take this striking passage from the Duisburg Nachlass, written some 6 years before the A-Deduction:

The synthesis contains the relation of appearances not in the perception but in the concept. That all relation in perception nevertheless presupposes a relation in the concept indicates that the mind contains in itself the universal and sufficient source of synthesis and all appearances are exponible in it. (Refl 4681, 17:667 [Kant 2005:174; emphasis added]) 
In the A-Deduction, Kant clearly aims at providing a regressive analysis of knowledge by explaining the "threefold synthesis, which is necessarily found in all cognition" (A97), where knowledge is the explanandum and synthesis the explanans. Also, Kant argues that the synthesis of apprehension and the synthesis of reproduction of the imagination are "inseparably bound" (A102; trans. Kemp Smith) and that without recognition in the concept "all reproduction in the series of representations would be in vain" (A103). This suggests that neither syntheses can operate singly, in isolation from the others. However, A124 appears to lend support to Allais's reading. There, Kant argues that it is first by means of the unity of apperception that "concepts that belong to the understanding can come about, but only by means of the imagination in relation to the sensible intuition", and that the unity of apperception "must be added to the pure imagination in order to make its function intellectual". He continues: "For in itself the synthesis of the imagination, although exercised a priori, is nevertheless always sensible, for it combines the manifold only as it appears in intuition [...]" (boldface mine). However, I contend that this passage must be read in the context of the regressive analysis of the possibility of knowledge, not as if the unity of apperception, and hence the categories, and the imagination were to be seen as separably instantiated (see further Chap. 6).

Understandably, Allais wants to keep both syntheses, intellectual and figurative, separate, since like Hanna she insists on two modes of synthesising that are not necessarily coextensive or do not necessarily entail each other, and only one of which is due to the conceptual capacities of the understanding, which comports with the strict distinction that she emphasises between nonconceptual content, or the intuition of particulars, and concepts. In her and Hanna's nonconceptual construal of intuition, intuition must in and of itself contain a synthetic connection between the representations that constitute its content (its object-reference) independently of the categories and hence independently of intellectual synthesis. This function of an independent synthetic connection in intuition is putatively carried out by figurative synthesis. Figurative synthesis performs this function separably from the understanding and its synthetic activity.

In her most recent work (Allais 2015, 2016), it seems to me that Allais has not dramatically changed her view, although she now emphasises, 
importantly, that not all forms of binding are forms of synthesis in Kant's strong sense, so that intuition can be characterised by a kind of combination ("binding", as Allais calls it, referring to cognitive or empirical psychology) that is short of being a priori synthesis in Kant's sense. ${ }^{50}$ But she still appears to insist that there are pre-conceptual forms of synthesis in Kant's sense, such as the synthesis of the imagination, that may be required for the unity of intuition, but do not involve the categories (Allais 2015). This reading overly differentiates, as did her earlier reading (2009), between synthesis and the categories as applied to sensibility. However, Allais (2015:267) also acknowledges that categories just are rules of pure or a priori synthesis. But if this is true, it stands to reason to deny that, at least in the context of TD, rules of pure or a priori synthesis are separable from the categories, unless there are different kinds, or modes of application, of rules of pure or a priori synthesis; but if there are different kinds, or modes of application, of rules of pure or a priori synthesis, then another, higher kind of pure synthesis would be required to synthesise the different kinds, or modes of application, of rules of pure or a priori synthesis, and so forth. An infinite regress threatens. Thus, a priori or pure synthesis cannot be considered separable from the categories.

In the next section, I look at a crucial passage in the run-up to the actual argument of TD, namely, a passage which is often viewed as strong evidence for a nonconceptualist reading of TD. I believe that there are good grounds for this view. But the passage is not uncontroversial. Whereas nonconceptualists point out that here Kant grants the real possibility of intuitions that are not subsumed or amenable to subsumption under the categories, conceptualists argue that Kant only entertains the hypothetical possibility of appearances (or intuitions) not conforming to the categories.

\subsection{Reading A89-91/B122-3 Anew: Hypothetical or Real Possibility?}

I concur with the central contention of Hanna's and Allais's argumentation that Kant is essentially a nonconceptualist and not a conceptualist about the intuition of particular objects. Intuition is itself not already 
conceptual content, nor are conceptual capacities required for having an intuition of particulars (as long as these are seen as indeterminate objects). However, I object to the interpretation of intuition as in and of itself having objective validity, as Hanna (2005:257) and presumably Allais $(2009: 391,393)^{51}$ believe, or that an intuition objectively refers, where reference implies designation of an individual or a particular. For Kant, although intuition indeed depends on an object being given (V-Met/Schön, 28:484; B72), objectivity or objective validity strictly speaking is solely a function of judgement (B141-2), and, importantly, the individuality or particularity of an object cannot be established prior to an act of judgement (by means of the rules of apperception). As I have argued above, I also differ from Hanna and Allais in that I do not believe that figurative synthesis and intellectual synthesis can be shared out between intuition and concept such that intuition is by definition characterised by figurative synthesis, or that the synthesis of intuition can be seen as separable from the synthesis by means of concepts (i.e. the categories). Not all intuition is synthesised and only those intuitions are synthesised which are part of a judgement. ${ }^{52}$ Neither are figurative and intellectual synthesis two de re separable instances of syntheses or ways of synthesising. They are just formally distinguishable aspects of one instance of synthesising that ensues from an operation of the understanding, which manifests itself on both the sensible and intellectual levels of a judgement, in judgement. Figurative synthesis is not a different or distinct act of synthesising from intellectual synthesis. There is just one transcendental synthesis, which binds intuition and concept together. For McDowell, this is not a problem as he believes that in principle each intuition already shows the same "togetherness" that is manifest in a conceptual episode, whose "togetherness" is shown in the propositional structure of judgement. Insofar as it concerns a case of objective knowledge, my own reading is closer to McDowell's (notwithstanding the problems with his reading flagged earlier in Sect. 5.3).

Nevertheless, I believe Allais is right to insist that the necessary "mutual dependence" (2009:399) of concept and intuition does not hold for the mere perception but only for the cognition of objects, whereby, unlike Allais, I understand cognition in terms of knowledge, not in terms of the mere thought of objects. ${ }^{53}$ The necessary conditions for the 
perceptual presentation of particular objects are time and space, not the categories (Allais 2009:399-401). It should be observed though that space and time as forms of intuition are not the sufficient conditions for the presentation of particular objects in space and time. So the question is whether particular objects can be represented, or perceived, as distinct particulars objects in space and time by means of the forms of intuition alone, as Allais seems to believe (cf. Allais 2015). I would firmly negate that question (see Onof and Schulting 2015). The issue here is the difference between what are the conditions of intuition, which always depends on a given object in space, and the conditions of the perception of that given object as a spatially distinct object (I expand on this in Chap. 7).

Both Allais and Hanna rightly cite the passage at B122-3 in the Critique in support of their nonconceptualist reading of intuition. I believe this is indeed one of the most convincing passages in Kant's work against strong conceptualism. Kant writes:

The categories of understanding [...] do not represent the conditions under which objects are given in intuition. Objects may, therefore, appear to us without their being under the necessity of being related to the functions of understanding; and understanding need not, therefore, contain their a priori conditions. Thus a difficulty such as we did not meet with in the field of sensibility is here presented, namely, how subjective conditions of thought can have objective validity, that is, can furnish conditions of the possibility of all knowledge of objects. For appearances can certainly be given in intuition independently of functions of the understanding. [...] That objects of sensible intuition must conform to the formal conditions of sensibility which lie a priori in the mind is evident, because otherwise they would not be objects for us. But that they must likewise conform to the conditions which the understanding requires for the synthetic unity of thought, is a conclusion the grounds of which are by no means so obvious. Appearances might very well be so constituted that the understanding should not find them to be in accordance with the conditions of its unity. Everything might be in such confusion that, for instance, in the series of appearances nothing presented itself which might yield a rule of synthesis and so answer to the concept of cause and effect. This concept would then be altogether empty, null, and meaningless. But since intuition stands in no need whatsoever of the functions of thought, appearances would none the less present objects to our intuition. (A89-91/B122-3; trans. Kemp Smith) ${ }^{54}$ 
Often the emphasis in this passage from $\$ 13$ in the run-up to TD is put on the ostensible merely hypothetical nature of the thought that Kant puts forward here, namely that "in the series of appearances nothing presented itself which might yield a rule of synthesis and so answer to the concept of cause and effect". Here, Kant would appear to argue that since in that case there can be no knowledge of an object it must be excluded that appearances would lie in disarray (cf. A111) and would not already show, at least in principle, the conceptual unity that is required for knowledge.

Hannah Ginsborg, who espouses a conceptualist reading of Kant, is typical in this respect. She writes in regard to B122-3:

If we abstract from the role of [...] synthesis in perception then it does at least seem possible that appearances can be presented to us independently of the conditions of understanding, but once we have recognized the role of synthesis in perception, we are in a position to see that this apparent possibility is illusory. (Ginsborg 2008:71) $)^{55}$

Ginsborg believes that the possibility that Kant considers is merely hypothetical or counterfactual, ${ }^{56}$ and that he never considers this a real or metaphysical possibility, viz. that appearances would in fact be presented to us independently of the understanding and not structured by the understanding so as to yield knowledge. Perhaps Ginsborg means that appearances that have objective validity cannot be independent from the understanding, as it is the understanding which confers objective validity on them. And that is certainly right, because it is trivially true. But the way in which she puts it makes it appear as if she believes that all appearances whatever cannot be independent from the understanding, regardless of the question about their objective validity. And that is clearly tantamount to an existential claim not licensed by Kant's argument at B122-3.57 The existential claim underlying both weak and strong conceptualism comes down to the negative existential statement that sensory content that is in principle non-conceptualisable does not exist. Strong conceptualism, which states that sensory or conscious content must be conceptualised, must be distinguished from weak conceptualism, which states that although sensory or conscious content must be able to be conceptualised, it does not depend on conceptuality for its 
existence. However defined, conceptualism in any case denies, in principle, that there could be sensory or conscious content (appearances) that is not conceptualisable; weak conceptualism only states that there could be de facto nonconceptualised content, but does not allow, in principle, that there could be content that is not conceptualisable or apt to conceptualisation. On weak conceptualism, any content at any rate necessarily entails conceptualisation, even if there could be the occasional unconceptualised intuition. Both weak and strong conceptualism therefore conflict with essentialist content nonconceptualism, which argues that there are intuitions which resist conceptualisation in principle (that is, are not conceptualisable).

Conceptualism of both variants implies that we could somehow establish the sensory content's or intuition's disposition to being conceptualised or being subsumable under concepts (categories), which on Kant's Copernican hypothesis - that is, the hypothesis that we only know a priori of things "what we have put into them" (Bxviii) - we are in principle not able to do. On Kant's account of what is possible to know, we cannot possibly know that there are not any sensory content or intuitions (any appearances) that elude conceptualisation, precisely because we only know of things what we have put into them beforehand by virtue of a priori synthesis. And what cannot be determined by virtue of conceptualisation through a priori synthesis, can neither be known. The transcendental truth that the unity of understanding is necessary for a synthesis of causally linked appearances and hence for the possibility of knowledge does not imply the truth of the existential claim that all appearances necessarily conform to the unity of the understanding and synthetically hang together (in an a priori way). That we cannot make cognitive claims about objects but by employing concepts and applying them to appearances does not in the least imply that appearances must be conceptualised (strong conceptualism) or even be subsumable under concepts (weak conceptualism).

But, in fact, Kant does not make the existential claim to the effect that the real possibility of appearances not conforming to the unity of the understanding would be excluded. (At least he does not here at B122-3; sometimes he does appear to make that claim, especially in the A-version of TD, e.g. at A111, A119, A123). ${ }^{58}$ First, towards the 
end of the quoted passage at A89-91/B122-3, Kant clearly asserts that even if appearances were to lie in a chaos "[a]ppearances would nonetheless offer objects to our intuition, for intuition by no means requires the functions of thinking" (A90-1/B123). As Carl (1992:124n.20) suggests, Kant's talk of "objects" here must be taken in the broad sense, namely in the sense that objective perceptions are representations of objects (Gegenstände). "Objects" here means "[a]ppearances", which "to the extent that as objects they are thought in accordance with the unity of the categories, are called phaenomena" (A248-9; emphasis added). All phenomena are appearances, but not all appearances are phenomena, for not all appearances are "thought in accordance with the unity of the categories". Appearances insofar as they are not phenomena in the sense defined, are those objects (Gegenstände) of which Kant speaks here at B122-3, and which are in no need of the functions of the understanding (i.e. are not "thought in accordance with the unity of the categories"). This, by implication, excludes the possibility that there would be objects that are phenomena which are in no need of the functions of the understanding, as this amounts to a contradiction, but it strongly suggests the real possibility of appearances that just amount to nonconceptual content or blind intuition.

At A111, in a passage similar to the one at B123, Kant hypothesises about the possibility that "a swarm of appearances [...] fill[s] up our soul without experience ever being able to arise from it", whereby "all relation of cognition to objects would also disappear, since the appearances would lack connection in accordance with universal and necessary laws" (cf. A122). In that case, "intuition without thought" (gedankenlose Anschauung) would be possible, but it would "never [be] cognition [Erkenntniß], and would therefore be as good as nothing for us". ${ }^{59}$ From the immediately preceding passage (A110), where he argues that " $[\mathrm{t}]$ here is only one experience, in which all perceptions are represented as in thoroughgoing and lawlike connection" (boldface mine), it appears that Kant excludes the possibility that one could have an epistemically relevant perception or intuition that does not belong to unitary experience grounded in "a transcendental ground of unity" (A111), but this does not imply that he excludes the real possibility of "intuition without thought" (gedankenlose Anschauung). In fact, in the hypothetical 
"swarm" case of a total lack of universal and necessary law-governedness, "intuition without thought" would still be really possible, but it would have no real relevance for us as cognisers. ${ }^{60}$

By contrast, with respect to the passage under discussion here (B1223), Brady Bowman has argued that Kant cannot rule out the logical possibility that appearances "appear to us without necessarily having a relation to the functions of the understanding", but that he does rule out the "real" or "transcendental" possibility that "appearances and concepts come apart" (2011:422). That Kant cannot rule out the logical possibility of them coming apart, is of course because objects are not analytically deducible from concepts: a world is conceivable, where objects do indeed come apart from the understanding. Likewise, Gomes (2014:6) argues that "we are not forced to treat the possibility expressed at A90/B123 as metaphysical", i.e. as constituting a real possibility. According to Gomes, the indicative können in B122 (3:102.26) is compatible with "the three paragraphs which end that section (A89-92/ B122-4) operating under an assumed 'for all we know' operator". In the text part that Gomes refers to (3:103.9-17), Kant employs the subjunctive. ${ }^{61}$ In light of the textual evidence, I believe that Bowman's and Gomes's interpretations are not compelling.

As we have seen with Ginsborg, it appears that some conceptualists conflate <all appearances> and <all objects of possible experience> (see also Bowman 2011). On account of Kant's theory of experience, it is analytically true that, necessarily, each and any object of possible experience is determined by the categories of the understanding, for an object is by definition a manifold of representations united by virtue of the categories. However, 'appearance' and 'object' in the sense of its definition at $\mathrm{B} 137^{62}$ are not equivalent terms. According to Kant's definition at the outset of the Transcendental Aesthetic, an appearance is an "undetermined" object of an empirical intuition (B34/A20), i.e. a manifold of an intuition that has not yet been united. ${ }^{63}$ Hence, an appearance, which is an intuition that has not yet been united, is not already objectively valid, against the view of Hanna (2008:258) and Allais (2009:391ff.), who claim that an intuition already by itself, intrinsically, refers objectively. The class of appearances is therefore much greater than the class of objects of possible experience. The former 
class does not only contain all possible objects of experience, but also all those appearances which only have subjective validity and never attain to objectivity, 'Praussian' subjective objects, say (see Prauss 1971:16ff.), which thus do not belong to the latter class. Not all appearances are therefore from the outset, as mere empirical representations or "species of representation" (A372; trans. mine; cf. B242ff/A197ff.), related to the understanding, as the conceptualist believes. Or, not all appearances are phenomena. ${ }^{64}$

Secondly, the goal of TD concerns establishing the a priori rules under which our perceptions, which are not already by themselves categorially determined, stand under the categories so as to yield objective knowledge, that is, knowledge of a priori necessary law-governed connections. As Allais (2009:399) rightly insists, establishing the rules of intuition as such is not at issue in TD, since these had already been established in the Aesthetic. Therefore, a clear distinction must be heeded between the goal of the Aesthetic and that of TD, even if it is true that in the second half of TD, in the famous and much discussed note to B160-1, Kant seems to alter his view on the way in which time and space must be regarded. ${ }^{65}$ However, the argument there is that the unity of space, about which in the Aesthetic Kant still maintained that it belonged to sensibility, is first constituted by virtue of the synthetic act of the understanding insofar as an objective grasp of the unity of space is concerned. Space and time as such, as "forms of intuition", themselves do not yet contain the synthetic unity which they only have as "formal intuitions" as a result of that synthetic act. ${ }^{66}$ This by no means implies that the a priori forms of space and time, which are the necessary forms of each and any intuition, are in and of themselves subject to the rules of the understanding or indeed show that synthetic unity which is required for objective knowledge of spatiotemporal objects. ${ }^{67}$ In other words, Kant's goal in TD is precisely to show that despite the real gap between the forms of intuition and the functions of the understanding, intuitions or appearances are indeed subsumed under the functions of the understanding if and only if we apprehend, by means of our capacity to judge, appearances as objects for our understanding. That is, the claim is that intuitions or appearances are determined by the unifying functions of the understanding if and only if the understanding apprehends them 
as determined by its functions; the understanding can only determine what it apprehends as determined by its functions.

The biconditional nature of the above-formulated claim evinces the radically subjectivist standpoint of Kant's theory of knowledge that I have been stressing in the preceding chapters. Determination and thus conceptualisation of intuitions is conditional on an a priori subjective act of determination, which is the act of synthesis that is expressed by transcendental apperception. If there is no such act, no conceptual determination of intuitions takes place. But this, of course, does not imply the negative existential claim that there could not be intuitions that amount to a form of subcognitive mental content, that is, merely subjectively valid perception, or appearances in the broad sense. Conceptualists (bar McDowell) tend to overestimate the scope of the transcendental subjectivity involved in cognitive determination and to ignore the conditional nature underlying it, which restricts the scope of the determinative function of subjectivity (that is, the conditional that "intuitions are determined by the functions of the understanding if and only if the understanding apprehends them as determined by them"). Nonconceptualists, on the other hand, either ignore, underestimate, or dismiss ${ }^{68}$ the subjective/active element of conceptual determination which first constitutes cognition or knowledge, and hence fail to explain how intuition and conceptuality do in fact connect up in actual cases of knowledge. By not considering Kant's subjectivism, as I have defined it, they thus vitally fail to address the central explanatory goal of TD.

It is of course not the case that in TD Kant backtracks on the absolute distinction between sensibility and the understanding. Instead of showing how to bridge the gap between intuition and concept, as some conceptualists appear to believe, ${ }^{69}$ Kant rather wants to demonstrate how from their union knowledge first arises. There is nothing essential about intuitions that would make them subsumable under the categories or which shows that they have a certain disposition to being so subsumed. Precisely because nothing in terms of essential connections or a pre-established harmony, say, binds sensibility and the understanding, Kant is presented with the problem that requires TD, namely, given their irreducible distinction, how do sensibility and understanding link up in an a priori way so as to yield knowledge? 


\subsection{Conclusion: Kant's Moderate Conceptualism}

We have seen that the conceptualist position, both in its 'weak' and 'strong' variants, is committed to a modally intemperate claim regarding the necessary conceptualisability of intuitions (or appearances), which is not warranted by Kant's text in A89-91/B122-3. The modally intemperate claim says that

(M) Necessarily, all intuitions are subject to the categories as the conceptual conditions under which knowledge of objects is possible (that is, intuitions either are or must be able to be subsumed under the categories)

$\mathbf{M}$ is tantamount to conceptualism (in either variant), the view that Hanna and Allais argue against. The analysis of B122-3 in Sect. 5.5 showed that $\mathbf{M}$ cannot be correct. It is not true that for any and all intuitions it holds that, necessarily, they correspond or conform to concepts to yield cognition and hence are subject to the a priori rules of synthesis constraining such cognition. If true, $\mathbf{M}$ would imply that we would know that, necessarily, all sensory content would be conformable to the universal relations among them that enable their connectedness as intuitions by means of which we know objects. This would mean that, as Kant writes, "we would be able to determine antecedently everything that can be an object for us at all", in other words, that "we had complete insight into all of our sensitivity and form" (Refl 5262 [1776-78], 18:135 [Kant 2005:223]). But clearly we do not have "complete insight into all of our sensitivity", and hence we cannot know that, necessarily, all sensory content is connected in accordance with rules that enable knowledge.

Also Kant's famous adage at A51/B75, which seems to assert the absolute inseparability or correspondence of concept and intuition, shows on further analysis that $\mathbf{M}$ cannot be right. For Kant writes towards the end of that passage that "[o]nly from their unification [i.e. the understanding and the senses, D.S.] can knowledge arise" (trans. emended). This suggests a hidden antecedent in the argument: it does not concern an absolutely necessary unity between intuition 
and concept, which in fact would contradict Kant's insistence on their irreducible difference (cf. B29), but a conditionally necessary unity. ${ }^{70}$

That only a conditionally necessary unity between intuition and concept is at issue is conveyed by $\mathbf{M}^{*}$, which states:

$\left(\mathbf{M}^{*}\right)$ Necessarily, if intuitions are to be seen as contributing to possible knowledge of objects, then intuitions are subsumed under the categories as the conceptual conditions under which knowledge of objects is possible.

Kant reasons that if we take there to be knowledge, and given that knowledge consists of both concepts and intuitions and of their synthetic unity, then we must assume that our sensibility corresponds to our conceptuality in accordance with a priori rules, for knowledge is only explainable from that correspondence. ${ }^{71}$ Note that Kant's argument in TD is not conditional in the sense that the categories do not necessarily apply to all spatiotemporal objects. Rather, the argument is conditional in the sense that if there is knowledge of spatiotemporal objects, and given that sensible intuition or sensibility is our immediate access to these objects and in that sense to be seen as a necessary contribution to knowledge, then sensible intuition or sensibility must be seen as subject to the categories to cooperate in the constitution of such knowledge. And given that there is knowledge, sensible intuition or sensibility is thus subject to the categories. Importantly, this does not imply that all sensible intuition is subject to the categories simpliciter, or that, necessarily, sensible intuition is subject to the categories, or that, necessarily, sensible intuition is amenable to being subsumed under the categories, which is what Kant's argument would be on account of M. Nor of course does this in and of itself show how sensible intuition is seen to be subject to the categories (the how question will be the topic of Chap. 7).

The conditional structure of the argument about the intuitionconcept relation $\left(\mathbf{M}^{*}\right)$ is consistent with the globally regressive character of TD. ${ }^{72}$ The regressive character of TD is shown in the way that its argument takes the fact of experience (or knowledge) as a premise and regresses to the necessary conditions of experience (or knowledge), 
based on the idea that experience (or knowledge) is built up of two formally separable elements, intuition and pure concepts, that constitute experience or knowledge to the extent that they are conjoined. Although Allais (2009:402) professes to base her reading on Ameriks's (1978) regressive interpretation, her nonconceptualist reading of intuition as intrinsically characterised by figurative synthesis in sharp contrast to conceptuality as intrinsically characterised by intellectual synthesis, as we saw in Sect. 5.4, reveals a much too rigid view of Kant's formal distinctions. By concentrating on the independence of intuition from the understanding, she skirts around the very crux of Kant's theory of experience, namely, to explain how intuition and concepts together enable experience or knowledge, and how the formally separable elements are to be seen contributing to it together. The distinction between the different syntheses is not an ontological distinction between faculties or powers or ways of representing that either are or are not coextensive, whereby figurative synthesis (or any form of binding) is simply the synthesis (or binding) of intuition in contrast to, and numerically distinct from, the intellectual synthesis of concepts through the understanding. The differentiable syntheses are the joint necessary transcendentallogical conditions of knowledge which operate their functions integrally and cannot be shared out between intuition and the understanding. If we base our reading on the A-version of the threefold synthesis, no synthesis performs its function separably from the other two syntheses for, as Kant indicates in the Leitfaden, that function is one and the same act of the understanding in judgement. Here lies the forte of Kant's central argument for an original unity of the two stems of knowledge. At the same time, that argument is moderated by the fact that the conditional structure of $\mathbf{M}^{*}$ precludes Kant from claiming that perception and intuition themselves are already conceptual or even proto-conceptual, or indeed amenable to being conceptualised, as Longuenesse appears to argue, when she says that a certain conatus, i.e. the capacity to judge, "pervades the totality of our sensible perceptions" (1998:196, 208). There is nothing about perception or intuition which shows that they have a conatus towards being conceptualised or judged about.

The central question in TD is and remains: What needs to be presupposed, in terms of a priori capacities, in order for knowledge to be possible? 
Kant argues, on the basis of regressive analysis, that a synthesis of apprehension must at least be presupposed, but since such a synthesis of apprehension is inadequate for the constitution of knowledge, also a synthesis of reproduction is required, and since neither a synthesis of reproduction is sufficient, a further synthesis of recognition is required (for a detailed account of the argument of the threefold synthesis in A, see Chap. 6). Kant does not mean that each of these syntheses operates in separation from the others, or in abstraction from them, as if it concerned the consecutive phases of an underlying psychological process that could either result or fail to result in knowledge, as McDowell and latterly Pippin appear to think (see Sect. 5.2). This would immediately produce an infinite regress problem. That is to say, if synthesis of apprehension were to be operated separately, what would see to it that it becomes a synthesis of reproduction? Which more originary synthesis would be responsible for the synthesis of apprehension becoming a synthesis of reproduction? This surely cannot non-question-beggingly be the synthesis of reproduction itself. But perhaps it is the synthesis of recognition that is the more originary synthesis that connects the two together. But what then is responsible for the synthesis of recognition effectively becoming a well-formed proposition that articulates a judgement rather than just being a reproduction of more or less ordered series of sensations? Or is the synthesis of recognition the effective judgement? ${ }^{73}$

One may argue that the threat of a vicious regress still haunts the account in the A-Deduction. To remove any semblance of regress or misplaced psychology, I believe that in the B-Deduction Kant relinquishes the explicit threefold character of synthesis (but see Chap. 6 for a reading of the threefold synthesis that is compatible with the B-Deduction account). In complete conformity with the Leitfaden (A79/B104-5) and confirming my thesis of Kant's radical subjectivism, in the B-Deduction the act of synthesis is attributed entirely to the understanding, which by means of one function establishes both a connection, or an intellectual synthesis, on the level of concepts (as formal unities) "by virtue of the analytical unity" and a connection, or a figurative synthesis, on the level of the content of concepts "by virtue of synthetic unity". ${ }^{74}$ The synthesis of apprehension is the figurative synthesis in the domain of sensibility, whereas the figurative synthesis is 
the effect of the intellectual synthesis of the understanding. Kant says that the imagination (a.k.a. figurative synthesis) is the mediating term between sensibility and the understanding (B164), which binds the two together (this will be argued in more detail in Chap. 7). But this does not mean that it has a separable intermediate status. McDowell comes closest to Kant's meaning, when he asserts that the unity of the imagination is not "an amalgam, however intimately bound together, of components that belong severally to sensibility and understanding" (2009a:124).

However, unlike McDowell, Hanna and Allais are right in maintaining that intuition as such is not necessarily or at least not yet categorially determined. There are intuitions that not only are not conceptualised de facto but also need not or indeed could not be conceptualised, because they are essentially nonconceptual and so resist conceptualisation. In line with Hanna's and Allais's nonconceptualism about intuition, it is also my view that intuition and concept are not, or at least need not be, coextensive; they are necessarily coextensive only in their connection in an actual judgement, in actual cases of knowledge, in conformity with $\mathbf{M}^{*}$. It is the relation between intuition and concept which is conceptual, not intuition itself. That relation is established solely by a conceptual action that Kant calls the bringing to the concept of synthesis (A78/B103-4), which results in judgement. McDowell's unwarranted quasi-Hegelian move is that he reads the capacity responsible for the possibility of judgement, which is a conceptual capacity, into sensibility tout court.

However, contrary to what nonconceptualists such as Hanna (2008) believe, something that is essentially nonconceptual can hardly be seen as the a priori and necessary ground or basis of something that is essentially conceptual. Nor can nonconceptual content be seen as synthesised content (in Kant's sense) or indeed as objectively referring. Intuitions may be immediately related to a spatially given object, but they are not determinate perceptions of spatially distinct and distinguishable objects or particulars. No form of nonconceptualism can explain what is the a priori synthetic-unitary ground for two essentially different elements, intuition and concept, for those instances in which intuition and concepts are necessarily coextensive, namely when there is an 
effective claim to knowledge, a judgement. This shows the failure of Kantian nonconceptualists to recognise Kant's radically subjectivist position about the possibility of knowledge. But what is undoubtedly true about the nonconceptualist position is that intuition is in and of itself not already conceptual, or in McDowell's words an "actualization of conceptual capacities". Only in relation to the concept, as part of an actual judgement, and from the perspective of an epistemic agent, is intuition brought to the concept through an act of pure synthesis, an act of the judging subject.

In conclusion, Kant may be called a conceptualist with respect to the possibility of knowledge with the proviso that intuition is not in and of itself conceptual or even proto-conceptual. Bridging the gap between the essentially non-conceptual, intuition, and the conceptual constitutes of course the heart of Kant's project in TD.

\section{Notes}

1. In German it says: "dadurch überhaupt ein Gegenstand gedacht wird (die Kategorie)", translated by Kemp Smith as "through which an object in general is thought (the category)", which is apt since Kant means to refer to the notion of the unity of apperception as defining the concept of an object in general (cf. A109-10; A104-5), whereas in the sections that follow the quoted one, Kant aims to account for the a priori possibility of particular objects, namely, spatiotemporal objects of human sensibility.

2. See Schulting (2012b) for a detailed account of the 'first step' of TD. See also Chaps. 2, 3 and 4 (this volume).

3. More specifically, the terms 'intuition', 'appearance' and 'sensible content' can be defined in the following way. Intuition is Kant's designation for a sensible way of cognising (B33/A19), which relates "immediately to the object" (B376ff./A320ff.; cf. V-Met/Schön, 28:482, 484; Prol, 4:281), whereas for Kant sensory content, as the label says, points more directly to the empirical content of such cognising, what Kant calls "sensation" or the "material" in an "appearance", which is the unbestimmte Gegenstand of an "empirical intuition" (B34/A20). In the Stufenleiter (B376/A320), Kant says that "perception" 
is "sensation" when it concerns a "modification of [one's] state", but cognition when it is a perception of something objective. And this is again subdivided into "intuition" and "concept", so that it seems as if for Kant both "intuition" and "concept" are objective perceptionsbut see Wolff (1995:62-63), who asserts that "intuition" is not genuine knowledge, which is confirmed by Kant's position that only in their conjunction intuitions and concepts yield knowledge; cf. FM, 20:325: "Knowledge by means of concepts is called discursive, by means of intuition, intuitive; in fact, knowledge requires the conjunction of the two, but each is named for the ground of determination to which I always primarily attend" (Kant 1983:181). See also V-Met/Volckmann, 28:404: "All our knowledge [Erkentni $\beta]$ consists of judgements and these must have an object, the mere intuition [bloße Anschaunng] is not knowledge [Erkentniß]" (trans. mine). As regards the term 'appearance', this can also be taken in two senses: either an appearance is just a "mere mode of representation [bloße Vorstellungsart]" (A372), i.e. an indeterminate object of an intuition, which as such is not distinguishable from the intuition, or an appearance is a phenomenon, namely, "to the extent that as object [it is] thought in accordance with the unity of the categories" (A248-9), i.e. an object as a unity of representations. All phenomena are appearances in the first sense, but not all appearances are appearances in the second sense. I return to this latter aspect below, as the distinction is relevant to how one reads the conclusion of the 'second step'.

4. See e.g. Pippin (2013:377, 381), who refers to Sellars (1967).

5. A distinction should be made between, on the one hand, intuitions that are (or are not) subsumed under the categories and, on the other, intuitions that are (or are not) subsumable under the categories. For intuitions can, not only not de facto be subsumed under the categories, but also be incapable of being subsumed under the categories. Therefore, all subsumed intuitions are ipso facto subsumable, but not all intuitions are subsumable. This distinction is important for an understanding of the position of essentialist nonconceptualism and will be spelled out in the course of this chapter; moreover, the question of the subsumability of intuitions seems implied by the very starting point of TD. However, to differentiate between the effective application and the applicability of the categories to intuition, as Grüne (2011) suggests, seems irrelevant, as the application of the categories is relevant 
in cases of knowledge only (whereas it is not a matter of course that intuitions contribute to knowledge). The categories either apply, in the case of objectively valid representations, or they do not, in the case of subjectively valid representations or representations that fail to apply to empirical objects. The issue of applicability, then, concerns the question whether or not categories effectively apply to intuition in the various possible cases. The distinction between effective application and applicability suggests that there is a possibility that categories are applicable to intuitions but are not effectively applied. This view, it seems to me, only leads to regress problems. For if categories are applicable to intuitions, but not yet effectively applied, then what makes it the case that they are so applied?

6. (Strong) conceptualism is precisely the view that "we cannot be perceptually presented with a particular independently of the application of concepts" (Allais 2009:386).

7. I.e. children have intuitions that occur independently of conceptual activity (see V-Anth/Collins, 25:10; V-Anth/Fried, 25:473).

8. V-Lo/Wiener, 24:846; Log, 9:65; Anth, 7:196; DfS, 2:59ff.; cf. KU, 5:464n.

9. I want to abstract here from the standard distinction between 'state nonconceptualism' and 'content nonconceptualism'. Content nonconceptualism asserts that the content of intuitions and the content of concepts are different in kind, so that the intuitional content fundamentally exceeds our conceptual capacity, whereas state nonconceptualism asserts that, although intuitions and conceptual assertions show the same content, a subject can be in a state in which she hasn't got at her disposal concepts with which she can make assertions about the content of her intuitions. The distinction between content and state nonconceptualism seems irrelevant for the issue of the dependency of intuitions on the functions of thought or conceptual capacities, for the functions of thought or conceptual capacities concern the relation between intuitions and a priori concepts, which content nonconceptualism by definition seems to foreclose. On the other hand, state nonconceptualism seems to imply that, although a subject can be in a state in which she only has intuitions and hasn't got at her disposal concepts with which to describe these intuitions, the mental content of those intuitions is always already conceptual. For this reason, one could argue that state nonconceptualism is only nonconceptualism in a very broad 
sense (Hanna 2013a:5). Hanna believes that content nonconceptualism is the only legitimate form of nonconceptualism. In order however to avoid the aforementioned radical consequence of content nonconceptualism, namely that it apparently forecloses the possibility of a relation between intuitions and concepts, one distinguishes between 'absolute' or 'essentialist' and 'relative' or 'non-essentialist', or 'strong' and 'weak' nonconceptualism. Relative (non-essentialist, weak) nonconceptualism leaves open the possibility that despite the fundamental difference between intuitional content and conceptual content the content of intuitions is articulated in conceptual assertions (Allais 2009:386). See further Schulting (2015:564-565n.7, 569-570n.19).

10. For more discussion of the debate that ensued after Allais (2009), see Allais (2016) and the new essays in Schulting (2016a).

11. I provide a detailed analysis of Kant's general notion of 'synthesis' in Schulting (2012b, Chaps. 6, 7). The role of synthesis in empirical intuition in both the A- and B-Deduction will be discussed in Chaps. 6 and 7 (this volume), respectively.

12. For a detailed analysis of this passage, see Schulting (2012b:141ff.).

13. For the origin of these terms, see Sellars (1997:76).

14. Cf. Sellars (1997:33) about the 'Myth of the Given'.

15. Kemp Smith has "expression" for Ausübung, which unfortunately loses the active aspect meant here by Kant. This is relevant, since McDowell systematically wants to deflate any such activity on the level of sensibility. See further below.

16. McDowell writes: "Visual experiences 'make' or 'contain' claims in that they are conceptual episodes, actualizations of conceptual capacities, and as such are to be understood on the model of linguistic performances in which claims are literally made" (2009a:10).

17. More recently, Cassam (2007) has argued something similar to what Sellars means. For Cassam, it likewise holds that an intuition is already conceptual but at the same time space must be made for what Dretske (1969) has labelled "simple seeings", non-epistemic seeings or percepts which are not in itself conceptual and are tantamount to the sheer reception of sensory material without involvement of concepts; importantly, a simple seeing is not a perception. Cassam paraphrases Dretske's account of the difference between "epistemic" and "non-epistemic" or "simple seeing": "[S]imple seeing is concept-free, since it implies nothing about the conceptual resources of the perceiver, and belief neutral 
in the sense that simply seeing $\mathrm{X}$ is compatible with no beliefs about $\mathrm{X}$. In both of these respects seeing $X$ is like stepping on $X$; one can step on $\mathrm{X}$ without recognizing it as an $\mathrm{X}$ or having any beliefs about $\mathrm{X}$. In contrast, perception is '(either by stipulation or common understanding) cognitively loaded' since 'some degree of recognition or categorization is essential to our perception of things' [...]. If this is right, then 'it is by no means obvious that one must perceive something in order to see it' [...]. Not knowing what a cup is prevents one from perceiving a cup but not from seeing a cup" (2007:133).

18. For a more detailed analysis of the Leitfaden, see Schulting (2012b, Chap. 5), and Longuenesse (2006).

19. Cf. Kant's use of the term Ausübung (B151), translated by Kemp Smith as "expression" and by Guyer/Wood, more appropriately and correctly, as "exercise". In a later essay, 'Avoiding the Myth of the Given' (2009b), McDowell has less qualms about employing the term 'exercise' in this context.

20. See again above note 17 .

21. But see Chap. 6 for a conceptualist reading of the A-Deduction.

22. The Guyer/Wood translation has "an effect of the understanding on sensibility"; this reflects Kant's standard meaning for the word Wirkung as one half of the cause-effect (Ursache-Wirkung) relation; the causal effect, of some sort, of the understanding on sensibility is thus meant here, that is, the effect of the causality of the spontaneity of the understanding, being a special kind of causality (see Schulting 2012b, Chap. 7; see also Chap. 3, this volume).

23. In a later essay (2009b:264), McDowell is though willing to countenance that the unity of intuition is due to a power to judge, but he also holds that the activity responsible for the unity of the intuition is "unconscious".

24. Cf. the debate between Pippin and McDowell on the issue of 'subjectivism' in Pippin (2005a, b) and McDowell (2009a:185-203), and Pippin $(2007,2015)$ for Pippin's last reply. I am in general agreement with Pippin's criticisms against McDowell on the issue of subjectivity. However, in a later text (2013:382-383), Pippin seems to diverge from the position delineated here, and to agree with McDowell, in that, according to Pippin, in demonstrative reference, that is, in intuitive representings, which, as Sellars put it, are nonetheless non-generally conceptual, we do not explicitly judge that $S$ is $P$, that is, apply sortal concepts to sensory material. But this raises at least the following 
problem for Kant: if the apperceptive act in a perceptual taking is not yet the act that produces an explicit judgement of the subject-predicate form (a 'judgemental taking'), then one wonders which other act makes it the case that we apperceptively judge that $S$ is $P$, rather than there just being merely an apperceptive (non-generally conceptual) perceptual taking there to be a book on the table, say. It seems as if Pippin suggests that non-generally conceptual takings (in perception) and attribution of sortal concepts in explicit judgements are two separately occurring possible instances of apperceptive taking, which is in tension with his other rightful claim that we should not take Kant to argue that conceptual form is somehow imposed on prior given nonconceptual sensory material. If, as Pippin claims, sensible content is always already a non-generally conceptually informed, i.e. an apperceived content, then the problem of the putative gap between nonconceptual content and conceptual form appears to have now, in his latest reading, been transposed to an ostensible gap between the instantiation of the apperceptive act in a perceptual taking and its instantiation in an actual judgement. In my view, for Kant, the actualisation of conceptual form in sensibility, by means of an act of apperception, happens solely in judgement, for any given empirical judgement. Pippin (and Sellars) seem to want to model, along quasi-Kantian lines, a kind of bottom-up analysis of how perceptual takings are already conceptually shaped, however inchoately, before they are articulated in judgements. But this kind of phenomenological specification is, to my mind, not available within the Kantian transcendental framework. Kant's analysis of conceptual form as a necessary transcendental condition of perception is based on the assumption of the givenness of experience, in the strong Kantian sense of experience as equivalent to knowledge claims (judgements) (B147), from which he then regresses to its conditions of possibility. Kant does not, in my view, argue for the conditions of possibility of the gradual generation of experience, as perceptual takings that may or may not result in judgemental takings.

25. See further Schulting (2012b:141ff.).

26. See also note 24 .

27. We can see a similar problem with Longuenesse's (1998) account of the twofold application of the categories: categories are said to govern syntheses of the sensible manifold, in a pre-discursive mode, and are only then effectively "reflected concepts" in discursive judgements. For discussion, see Schulting (2012b:33-38). 
28. McDowell tries to justify this potential/actual approach to the relation between intuitions and discursive intellectual activity by referring to Kant's own use of the modality in the formulation of apperception in the 'I think'-proposition at B131 (i.e. the verbal phrase "must be able") (see McDowell 2009a:265-266, 271). Presumably, this expresses the necessary possibility that all my representations are accompanied by an 'I think', but need not actually be so accompanied. But this is based on a (common) misreading of that verbal phrase. See my analysis in Schulting (2012a, b). See also Chap. 4 (this volume), specifically, Sect. 4.8.

29. See Pippin (2015:68-69) and note 24 above.

30. Here, I rely on the more succinct 2008 paper. See also Hanna (2011a, b, 2013b).

31. In the literature various types of nonconceptualism are distinguished, i.e. state and content nonconceptualism and weak and strong variants of nonconceptualism. Roughly speaking, a Kantian conceptualist regards the relation between intuition and concept such that no intuition exists without involving, at least in principle, conceptuality (broadly conceived). A Kantian nonconceptualist, by contrast, is someone who regards that relation in such a way that there is no necessary entailment between any arbitrary existing intuition (appearances, sensible content) and conceptuality (broadly conceived). See the definitions given at the outset of this chapter, and especially note 9 .

32. See also Grüne (2009) on blind intuition. Grüne's richly documented book also deals with the discussion of nonconceptual content, but her own reading is not classifiable as nonconceptualist strictly speaking. See further Chap. 6.

33. Cf. the discussion between Cassam (2008) and Longuenesse (2008) on the issue of a priori synthesis and regress.

34. Kant's spontaneous 'I' of transcendental apperception is of course, in a certain cognitively indeterminable sense, grounded in an ontologically more fundamental, but unknowable, noumenal substance. But this does not detract from the originality and spontaneity of transcendental apperception relative to empirical experience. Transcendental apperception, or what Hanna calls "higher level spontaneity", is at any rate not grounded in sensory content, however much synthesised by a putative "lower level" spontaneity. See again Chap. 3.

35. See Schulting (2012b, Chaps. 6, 8). See also Chap. 4 (this volume). 
36. I argue for the rigorous coextensivity between the analytic and synthetic unities of apperception in Schulting (2012b). See also Chap. 2 (this volume).

37. See further Schulting (2012b, 2015) and Chaps. 6 and 7 (this volume).

38. In the literature a distinction is made between absolute and relative nonconceptualism. Absolute nonconceptualism means that perception and belief are essentially or intrinsically different, while relative nonconceptualism indicates that a subject has mental content without possessing the relevant concepts to describe that content (see Allais 2009:386). See above note 9. The main difference between Hanna and Allais is that Hanna thinks Kant is an essential nonconceptualist, whereas Allais believes Kant is a relative nonconceptualist.

39. At B47/A32, Kant writes: "That representation [...] which can only be given through a single object, is an intuition." Thus, intuition could be seen as what in current language is considered a singular reference to an object or particular.

40. Usually, two criteria for intuitions are mentioned: (1) the singularity criterion (A320/B377; A19/B33; B47/A32), and (2) the immediacy criterion (V-Met/Schön, 28:484; A68/B93). But a third criterion can be singled out: the dependency criterion (V-Met/Schön, 28:484; B72; Prol, 4:281), for an intuition is dependent on a prior given object. For an account of the potential problems that arise for nonconceptualists who rely on a strong reading of this criterion, see Stephenson (2015).

41. See by contrast McDowell (2009a:32, 100-101). McDowell reads Kant's assertion at B159, i.e. the assertion that categories apply to "whatever objects may present themselves to our senses", such that even the presenting, in and through intuition, of objects does not happen "independently of its cooperation with the understanding". In the original Dutch article on which this chapter is based (see Schulting 2010:704n.76), I misquoted McDowell as referring to the passage following, at B160, where Kant writes that "everything that may ever come before the senses must stand under the laws that arise a priori from the understanding alone", but, as I pointed out in the aforementioned earlier version, this must clearly be read in the light of the sentence quoted by $\mathrm{McDowell}$; the "everything" means merely "objects" presenting themselves, not literally every and all representations (see further Chap. 7). Aaron Griffith advances a stronger conceptualist reading of this passage, by contending "that even sense perception without judgement stands under the 
categories" (2012:207). This is a standard reading but it makes no sense. How can sense perception which is not a judgement, and hence not an inseparable component of a judgement, still stand under functions of judgement that give it, the judgement, objective validity, i.e. the categories? A perception is either an inseparable component of an actual judgement, thus implying application of the categories, or it is not, which means that it is merely an intuition of an object. There is nothing essential about perception as such, "without judgement", that makes it amenable to standing under the categories, which are after all nothing but the logical functions of judgement (B143).

42. In his pre-Critical philosophy, around 1769, Kant still held the view that intuition provides "immediate cognition of individual things", but he also then believed in "intuitive concepts" (Refl 3957, 17:364 [Kant 2005:104]). After the Inaugural Dissertation (1770), it seems plausible that, since he gave up on the idea of 'intuitive concepts' and sought to explain how the intellect and sensible intuition work together to yield knowledge, he also relinquished the idea that intuition provides immediate cognition of individual things, separably from the intellect.

43. Cf. by contrast McDowell, who writes: "Kant urges that objects do not count as present to intuition unless what is given to the senses has categorial unity, $[\ldots]$ categories secure for intuitions a genuinely objective purport [...]" (2009a:100).

44. Compare Griffith (2012), who claims to argue for a less strong conceptualism (than Allais's), by holding the view that indeed categories are required for intuition, but not that one need employ empirical concepts for having intuitions. Strong conceptualism in his view would mean that empirical concepts are needed for intuition. It seems though that strong conceptualism for Allais just means the thesis that categories as general rules are required for the existence of an intuition (she also seems to conflate the two questions that Griffith wants separated; see further below). Griffith's weak conceptualism thus is still stronger than Allais's relative nonconceptualism (i.e. the view that intuition can but need not stand under the categories), so counts as strong conceptualism within Allais's perspective. Furthermore, I believe Griffith's strategy is not pertinent to Kant's analysis in TD, since that analysis only concerns the use of pure concepts and not empirical concepts, and therefore the controversial claim regarding the absolute distinction of intuition and concept - the claim that is central to the debate on Kant and nonconceptual content-only concerns the whether or no requirement of pure 
concepts or the categories for the possibility of intuition. The question regarding the application of empirical concepts is of secondary relevance, as their application requires at any rate the application of the categories, given that for Kant concepts are only employed in judgements and categories are nothing but the functions of judgement.

45. One could of course concentrate on the A-account of synthesis, as Allais indeed does (2009:396-397n.37) (see further below), and contend that only the synthesis of recognition involves concepts, not yet the synthesis of apprehension and the synthesis of the imagination. For a critique of such a reading of Kant's account in the A-Deduction, see Chap. 6.

46. See further Schulting (2012b:88-89, 247).

47. Cf. Allison (2012:35-36).

48. See also B154, where Kant identifies "the transcendental action of the imagination" with the "synthetic influence of the understanding on the inner sense" (emphasis added).

49. For a detailed analysis of what kind of combination is at issue in this important passage at the outset of the B-Deduction, see Schulting (2012b:141ff.). There, I argue that not all kinds of combination or connection of the manifold in an intuition are due to an act of the understanding. The kind of combination that is at issue at B129-30 is a priori, necessary synthesis.

50. This is not a novel thesis. See also Hoppe (1983) and my own account in Schulting (2012b:141ff.).

51. Allais is more careful in her formulations than I suggest here. See again the discussion in the preceding section. At any rate, it seems to me that Allais believes that intuition in and of itself refers to an already given object, and in this sense provides the objective validity that concepts (categories) require to have true application. For Allais, objective validity does not lie solely in the function of judgement, as on my view.

52. Compared to her earlier account in Allais (2009), in her book (Allais 2015) Allais is more precise in saying that intuition per se is not by definition characterised by synthesis, but she still believes that some form of a priori synthesis (i.e. productive imagination) does not require the categories. This contrasts with my view that all a priori syntheses are part of judgement, and only take place within it.

53. For a good analysis of the potential problems that face Allais's reading on this latter point, see Newton (2016). See also Chap. 4 (this volume), in particular Sect. 4.9. 
54. Other passages in TD that support nonconceptualism regarding intuition are B145 (" $[\mathrm{T}]$ he manifold for intuition must already be given prior to the synthesis of understanding and independently from it") and B132 ("That representation that can be given prior to all thinking is called intuition").

55. Also Allison (2001:38) thinks along those lines. Allison speaks of the "exorciz[ing]" of the "specter" of "transcendental chaos", which at B122-3 Kant supposedly holds before us as a threatening possibility; according to Allison, this exorcism is the central goal of TD. See also Allison (1996:49-50), where Allison refers to "the Kantian analogue of the Cartesian 'evil genius', a spectre that must be exorcized if the project of the Deduction is to succeed". Cf. Allison (2012:48, 2015:54).

56. Likewise, Grüne (2011:475) thinks the hypothesis in B122-3 has "only a didactic function". Cf. Bowman (2011:423) and Anderson (2015:352n.28). Anderson reasons that B122 should be taken "to be a description not of how things are, but of how they appear to be-they frame the difficulty that the argument of the Deduction is meant to overcome, and therefore indicate the very opposite of Kant's settled view". This view is hard to reconcile with the indicative mood of B122.

57. At A111-12, however, Kant indeed appears to argue that "all possible appearances", even "the entire sensibility", are "necessarily in agreement with the conditions of the thoroughgoing unity of self-consciousness, i.e., must stand under universal functions of synthesis [...]", which would endorse Ginsborg's reading. But compare the passage prior to this one, at A110: "[...] all appearances, insofar as objects are to be given to us through them, must stand under a priori rules of their synthetic unity [...]" (emphasis added), which points to a limiting condition on the relation between appearances and categories as "a priori rules of their synthetic unity".

58. See note 57 above.

59. Cf. the early Reflexion that is contemporaneous with Kant's letter to Herz from 1772, Refl 4636, 17:619-620: "(One can intuit something without thinking something thereby or thereunder.) All cognitions come to us through thinking, i.e., through concepts" (Kant 2005:151; emphasis added).

60. Cf. Refl 5221, 18:122.25-123.02.

61. For further discussion see Schulting (2015:571-572).

62. "An object $[\ldots]$ is that in the concept of which the manifold of a given intuition is united." 
63. At A108-9, Kant differentiates 'appearance' and 'intuition' thus: "Appearances are the only objects that can be given to us immediately, and that in them which is immediately related to the object is called intuition.”

64. See A120, which makes it clear that appearances are the data given in inner sense, before any synthesis is carried out.

65. That the projects of the Aesthetic and TD are naturally not completely separable is also suggested by Kant's words, in a passage prior to the above-quoted, that hint at the necessity of a transcendental deduction not just of the concepts of the understanding but also of space as a result of the ambiguity in the concept of the latter (see B120/A88).

66. See Onof and Schulting (2015).

67. Indeed, Onof and Schulting (2015) show that the sui generis unity of space, i.e. what can be called the unicity of space, is irreducible to conceptual unity. See further Chap. 7.

68. Hanna (2011b) believes that if Kantian nonconceptualism is true, then Kantian conceptualism is false, and consequently TD, which is centrally based on a conceptualist claim, is a failure. But Hanna's disjunctive reading is based on a failure to see the conditional structure of Kant's argument for the necessary conceptualisation of intuitions, and thus a failure to respect the radically subjectivist nature of Kant's conceptualism.

69. However, some conceptualists believe that there is no gap in the first place, hence their position that the possibility that Kant entertains at B122 is merely hypothetical.

70. See also the more detailed discussion of this passage in Schulting (2016b).

71. Cf. Refl 5221, 18:123.

72. See my detailed account of the regressive nature of TD in Schulting (2012b:61-75).

73. Hanna (2013b) has acknowledged this threat of a regress, if we read Kant's distinction, as he does, between figurative and intellectual synthesis as shared out between nonconceptual and conceptual content. (He aptly calls it the "the schmimagination vicious regress problem"). But it is unclear how he thinks it can be solved. See further Schulting (2015).

74. On the argument of MD (the Leitfaden section), see further Schulting (2012b, Chap. 5). 


\section{References}

Allais, L. 2009. Kant, Non-Conceptual Content and the Representation of Space. Journal of the History of Philosophy 47 (3): 383-413.

Allais, L. 2015. Manifest Reality. Kant's Idealism and His Realism. Oxford: Oxford University Press.

Allais, L. 2016. Conceptualism and Nonconceptualism in Kant: A Survey of the Recent Debate. In Kantian Nonconceptualism, ed. D. Schulting, 1-25. London and New York: Palgrave Macmillan.

Allison, H. 1996. Idealism and Freedom. Essays on Kant's Theoretical and Practical Philosophy. Cambridge: Cambridge University Press.

Allison, H. 2001. Kant's Theory of Taste. A Reading of the Critique of Aesthetic Judgment. Cambridge: Cambridge University Press.

Allison, H. 2012. Essays on Kant. Oxford: Oxford University Press.

Allison, H. 2015. Kant's Transcendental Deduction. An Analytical-Historical Commentary. Oxford: Oxford University Press.

Ameriks, K. 1978. Kant's Transcendental Deduction as a Regressive Argument. Kant-Studien 69 (3): 273-287.

Anderson, L. 2015. The Poverty of Conceptual Truth. Kant's Analytic/Synthetic Distinction and the Limits of Metaphysics. Oxford: Oxford University Press.

Bowman, B. 2011. A Conceptualist Reply to Hanna's Kantian NonConceptualism. International Journal of Philosophical Studies 19 (3): 417-446.

Carl, W. 1992. Die transzendentale Deduktion der Kategorien in der ersten Auflage der Kritik der reinen Vernunft. Ein Kommentar. Frankfurt a/M: Klostermann.

Cassam, Q. 2007. The Possibility of Knowledge. Oxford: Clarendon Press.

Cassam, Q. 2008. Reply to Longuenesse. Philosophy and Phenomenological Research 77 (2): 525-531.

Dretske, F. 1969. Seeing and Knowing. London: Routledge and Kegan Paul.

Ginsborg, H. 2008. Was Kant a Nonconceptualist? Philosophical Studies 137: 65-77.

Gomes, A. 2014. Kant on Perception: Naïve Realism, Non-Conceptualism and the B-Deduction. Philosophical Quarterly 64 (254): 1-19.

Griffith, A. 2012. Perception and the Categories: A Conceptualist Reading of Kant's Critique of Pure Reason. European Journal of Philosophy 20 (2): $193-222$.

Grüne, S. 2009. Blinde Anschauung. Die Rolle von Begriffen in Kants Theorie sinnlicher Synthesis. Frankfurt a/M: Klostermann. 
Grüne, S. 2011. Is There a Gap in Kant's B Deduction? International Journal of Philosophical Studies 19 (3): 465-490.

Hanna, R. 2005. Kant and Nonconceptual Content. European Journal of Philosophy 13 (2): 247-290.

Hanna, R. 2008. Kantian Non-Conceptualism. Philosophical Studies 137: 41-64.

Hanna, R. 2011a. Beyond the Myth of the Myth: A Kantian Theory of NonConceptual Content. International Journal of Philosophical Studies 19 (3): 323-398.

Hanna, R. 2011b. Kant's Non-Conceptualism, Rogue Objects, and the Gap in the B Deduction. International Journal of Philosophical Studies 19 (3): 399-415.

Hanna, R. 2013a. Kant, Hegel, and the Fate of Non-Conceptual Content. Hegel Bulletin 34 (1): 1-32.

Hanna, R. 2013b. 'The Togetherness Principle, Kant's Conceptualism, and Kant's Non-Conceptualism', supplement to 'Kant's Theory of Judgment'. Stanford Encyclopedia of Philosophy. http://plato.stanford.edu/archives/ fall2013/entries/kant-judgment/supplement1.html.

Hoppe, H.-G. 1983. Synthesis bei Kant. Berlin and New York: de Gruyter.

Kant, I. 1983. What Real Progress Has Metaphysics Made in Germany since the Time of Leibniz and Wolff?, trans. and ed. T. Humphrey. New York: Abaris.

Kant, I. 2002. Theoretical Philosophy after 1781, trans. and ed. H. Allison et al. Cambridge: Cambridge University Press.

Kant, I. 2005. Notes and Fragments, trans. and ed. P. Guyer et al. Cambridge: Cambridge University Press.

Longuenesse, B. 1998. Kant and the Capacity to Judge. Princeton: Princeton University Press.

Longuenesse, B. 2006. Kant on A Priori Concepts: The Metaphysical Deduction of the Categories. In The Cambridge Companion to Kant and Modern Philosophy, ed. P. Guyer, 129-168. Cambridge: Cambridge University Press.

Longuenesse, B. 2008. Cassam and Kant on "How Possible" Questions and Categorial Thinking. Philosophy and Phenomenological Research 77 (2): 510-517.

McDowell, J. 1996. Mind and World, 2nd ed. Cambridge, MA: Harvard University Press.

McDowell, J. 2009a. Having the World in View: Essays on Kant, Hegel, and Sellars. Cambridge, MA: Harvard University Press. 
McDowell, J. 2009b. Avoiding the Myth of the Given. In J. McDowell, Having the World in View: Essays on Kant, Hegel, and Sellars, 256-272. Cambridge, MA: Harvard University Press.

Newton, A. 2016. Non-Conceptualism and Knowledge in Lucy Allais's Manifest Reality. Kantian Review 21 (2): 273-282.

Onof, C., and D. Schulting. 2015. Space as Form of Intuition and as Formal Intuition. On the Note to B160 in Kant's Critique of Pure Reason. Philosophical Review 124 (1): 1-58.

Pippin, R. 2005a. Leaving Nature Behind, or Two Cheers for "Subjectivism". In R. Pippin, The Persistence of Subjectivity. On the Kantian Aftermath, 186-205. Cambridge: Cambridge University Press.

Pippin, R. 2005b. Postscript: On McDowell's Response to "Leaving Nature Behind". In R. Pippin, The Persistence of Subjectivity. On the Kantian Aftermath, 206-220. Cambridge: Cambridge University Press.

Pippin, R. 2007. McDowell's Germans: Response to "On Pippin's Postscript". European Journal of Philosophy 15 (3): 411-434 [quoted from Pippin 2015].

Pippin, R. 2013. Reason's Form. In The Impact of Idealism. The Legacy of Post-Kantian German Thought, ed. K. Ameriks, 373-394. Cambridge: Cambridge University Press.

Pippin, R. 2015. John McDowell's Germans. In R. Pippin, Interanimations. Receiving Modern German Philosophy, 63-90. Chicago: University of Chicago Press.

Prauss, G. 1971. Erscheinung bei Kant. Berlin: de Gruyter.

Schulting, D. 2010. Kant, non-conceptuele inhoud en synthese. Tijdschrift voor Filosofie 72 (4): 679-715.

Schulting, D. 2012a. Non-Apperceptive Consciousness. In Kant's Philosophy of the Unconscious, ed. P. Giordanetti et al., 271-303. Berlin and New York: de Gruyter.

Schulting, D. 2012b. Kant's Deduction and Apperception. Explaining the Categories. Basingstoke and New York: Palgrave Macmillan.

Schulting, D. 2015. Probleme des „kantianischen“ Nonkonzeptualismus im Hinblick auf die B-Deduktion. Kant-Studien 106 (4): 561-580.

Schulting, D. (ed.). 2016a. Kantian Nonconceptualism. London and New York: Palgrave Macmillan.

Schulting, D. 2016b. On an Older Dispute: Hegel, Pippin, and the Separability of Concept and Intuition in Kant. In Kantian Nonconceptualism, ed. D. Schulting, 227-255. London and New York: Palgrave Macmillan. 
Sellars, W. 1967. Some Remarks on Kant's Theory of Experience. Journal of Philosophy 64 (20): 633-647.

Sellars, W. 1992. Science and Metaphysics. Variations on Kantian Themes. Atascadero: Ridgeview.

Sellars, W. 1997. Empiricism and the Philosophy of Mind. Cambridge, MA: Harvard University Press.

Stephenson, A. 2015. Kant on the Object-Dependence of Intuition and Hallucination. Philosophical Quarterly 65 (260): 486-508.

Wolff, M. 1995. Die Vollständigkeit der kantischen Urteilstafel. Frankfurt a/M: Klostermann. 